\title{
Measurement and Simulation of the IAQ Impact of Particle Air Cleaners in a Single-Zone Building
}

Steven J. Emmerich

Steven J. Nabinger

U.S. Department of Commerce

National Institute of Standards and Technology Building and Fire Research Laboratory Gaithersburg, Maryland 20899
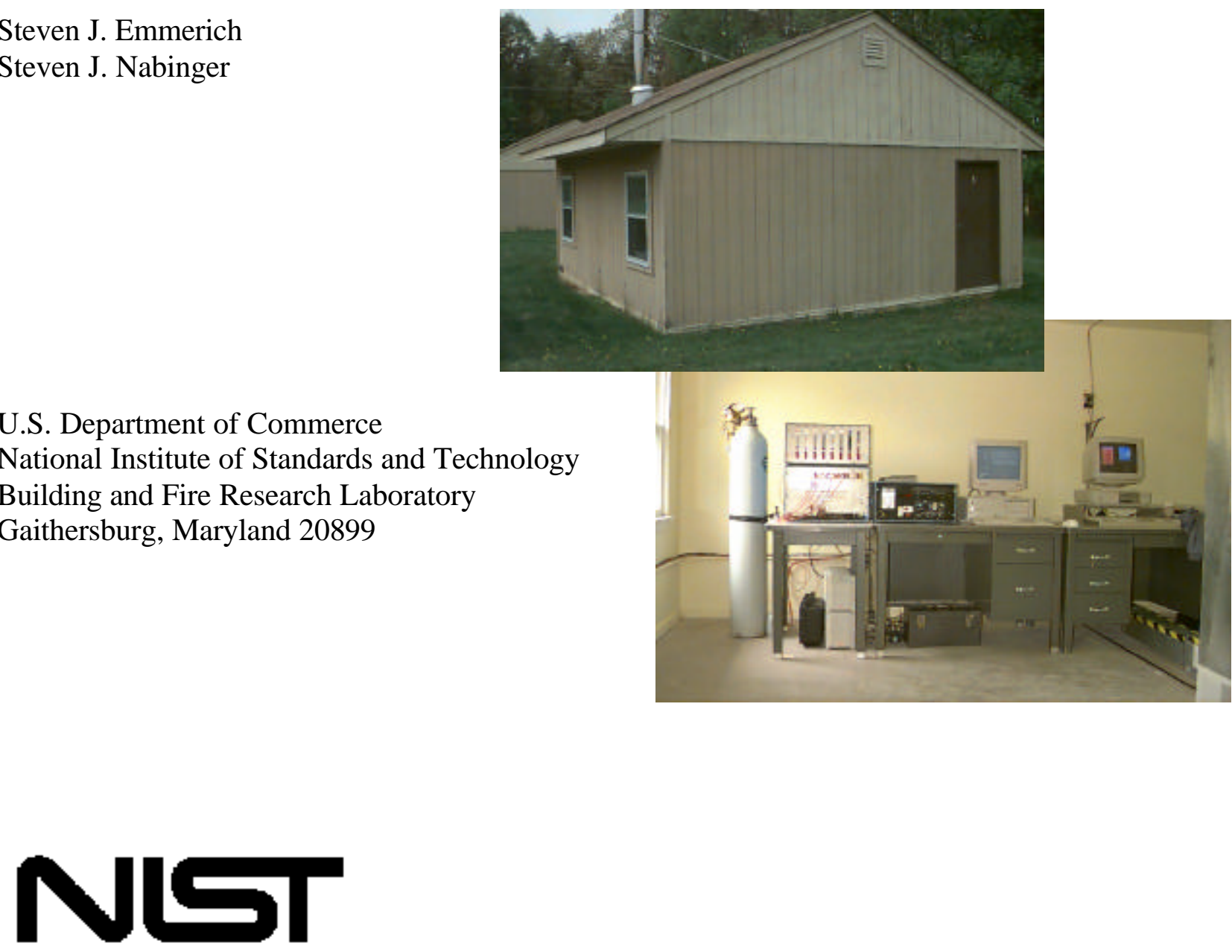

United States Department of Commerce Technology Administration

National Institute of Standards and Technology 


\section{Measurement and Simulation of the IAQ Impact of Particle Air Cleaners in a Single-Zone Building}

Steven J. Emmerich

Steven J. Nabinger

February 2000

Building and Fire Research Laboratory

Gaithersburg, Maryland 20899

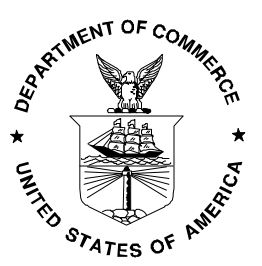

U.S. Department of Commerce

William M. Daley, Secretary

Technology Administration

Cheryl L. Shavers, Under Secretary for Technology

National Institute of Standards and Technology

Raymond Kammer, Director 


\begin{abstract}
This report describes the initial phase of an effort to evaluate the ability of multizone airflow and pollutant transport models to predict the impact of residential IAQ control technologies. Measurements of the performance of several particulate air cleaning devices and related particle transport parameters were performed in a one-room test house. These measurements were used to calculate building air change rates, particle deposition rates and penetration factors, and air cleaner removal efficiencies. Two separate $24 \mathrm{~h}$ tests were performed with two of the tested air cleaners, and the measured air change rates and particle concentrations were compared to predicted values obtained with the CONTAM model. For both tests, simulated $24 \mathrm{~h}$ average air change rates were within $5 \%$ of measured air change rates and simulated $24 \mathrm{~h}$ average particle concentrations were within $30 \%$ of measurements for all particle sizes. Simulations were also performed to predict the impact of the air cleaners compared to a typical furnace filter.
\end{abstract}

Key Words: air cleaners, airflow modeling, building technology, computer simulation, infiltration, multizone, residential buildings, and validation. 


\section{Table of Contents}

Abstract $i$

List of Tables $v$

List of Figures vii

Introduction 1

Background 1

Literature Review $\quad 2$

Experimental Procedure $\quad 4$

Test House $\quad 4$

Instrumentation $\quad 5$

$\begin{array}{lr}\text { Air Cleaners } & 9\end{array}$

Experimental Results 10

Infiltration Rates $\quad 10$

Deposition Rates $\quad 11$

Penetration Factors $\quad 13$

Filtration Efficiencies from Decay Tests 14

Filtration Efficiencies from Direct Measurements 17

Particle Generator Source Strengths 19

Ozone Generation $\quad 20$

$\begin{array}{ll}\text { Long Term Test of MAC5 } & 21\end{array}$

Simulation Procedure $\quad 23$

CONTAM Model $\quad 23$

Comparison of Predictions and Measurements $\quad 25$

Statistical Evaluation of Model Predictions 25

Infiltration Rates $\quad 26$

Tracer Gas Concentrations $\quad 26$

Mechanical Air Cleaner Performance $\quad 27$

Electronic Air Cleaner Performance $\quad 29$

$\begin{array}{ll}\text { Statistical Evaluation } & 31\end{array}$

Impact of Air Cleaners

$\begin{array}{ll}\text { Discussion } & 34\end{array}$

$\begin{array}{ll}\text { Acknowledgements } & 35\end{array}$

$\begin{array}{ll}\text { References } & 36\end{array}$ 


\section{List of Tables}

$1 \quad$ Summary of Total Decay Rates for Deposition Cases 13

2 Average Deposition Rates with HVAC System On and Off 13

3 Penetration Factors 14

4 Summary of Total Decay Rates for Air Cleaner Cases 15

$5 \quad$ Decay Test Filter Efficiencies (Subtracting System-Off Deposition) 16

6 Decay Test Filter Efficiencies (Subtracting System-On Deposition) 17

7 Direct Measurement Filtration Efficiencies 18

8 Particle Generator Source Strength 20

9 Average Ozone Concentrations During EAC1 Tests 21

10 Air Leakage Values 24 


\section{List of Figures}

$1 \quad$ Schematic Elevation of Test House 4

2 Schematic Floorplan of Test House 5

3 Schematic of HVAC System 6

4 Outdoor Particle Counts Sampled with and without Diluter 7

5 Measured Hourly Infiltration Rates (Wind Speed $<0.5 \mathrm{~m} / \mathrm{s}$ ) 10

$6 \quad$ Measured Hourly Infiltration Rates $\left(\left|\mathrm{T}_{\text {in }}-\mathrm{T}_{\text {out }}\right|<5{ }^{\circ} \mathrm{C}\right) \quad 11$

$7 \quad$ Mixing in Test House for Case d74 12

8 Sample In-duct Particle Counts for EAC1 18

9 Comparison of Filtration Efficiencies from Three Test Methods 19

10 Transient Ozone Concentration due to EAC1 Operation 20

11 Long Term Efficiency Test of MAC5 22

12 Correlation of Filter Weight and Relative Humidity 22

13 CONTAM Sketchpad Representation of Test House 23

14 Measured and Simulated Blower Door Test Results 24

15 Measured and Simulated Air Change Rates 27

16 Measured and Simulated Tracer Gas Concentrations 28

17 Comparison of Measured and Simulated Particle Counts with

18 Comparison of Measured and Simulated Particle Counts with Decay Test MAC1b Filtration Efficiency 29

19 Comparison of Measured and Simulated Particle Counts with Direct EAC1 Filtration Efficiency $\quad 30$

20 Comparison of Measured and Simulated Particle Counts with Decay Test EAC1 Filtration Efficiency $\quad 31$

21 Impact of MAC1b Compared to Furnace Filter 32

22 Impact of EAC Compared to Furnace Filter 33 


\section{INTRODUCTION}

This report describes experiments and simulations performed to evaluate the capability to accurately simulate the impact of particle air cleaners with a multizone airflow and indoor air quality (IAQ) model, in this case CONTAM. The first task of this effort was to review published studies relevant to the performance of particulate air cleaning technologies. Various aerosol transport parameters and the performance of several particulate air cleaners were then measured in a single-zone test house. Measurements and CONTAM predictions were then compared to evaluate the ability of the model to predict the performance of air cleaners and to identify any model development needs.

\section{Background}

There is increasing interest world-wide in the use of consensus performance standards for housing. The potential benefits include the removal of barriers to the acceptance of housing innovation in the global marketplace and the improvement of communications between producers and consumers leading to enhanced quality and performance of housing. However, the state-ofthe-art in IAQ regulations are building codes based on prescribed ventilation rates such as in American Society of Heating, Refrigerating and Air-Conditioning Engineers Standard 62-1999 (ASHRAE 1999). Standard 62 and many codes mandate ventilation rates based on occupancy and/or floor area for both residential and commercial buildings. This type of requirement makes it difficult to take credit for innovative IAQ control technology. It also ignores other important factors such as outdoor pollutant concentrations and variations in indoor source strengths.

A major effort is underway within the Building and Fire Research Laboratory (BFRL) of National Institute of Standards and Technology (NIST) to develop residential performance standards covering a number of building attributes, including indoor air quality (Persily 1999). Performance standards specify how components must perform instead of the manner in which that performance is to be obtained. The standards relevant to the indoor environment will ultimately be based on the indoor levels of specific airborne contaminants and thermal comfort parameters. Early versions of the standards, however, will likely be based on performance in terms of building ventilation rates due to the current lack of knowledge of human response to indoor pollutant levels and other environmental parameters. Because measuring ventilation rates, contaminant concentrations and thermal comfort parameters in a large number of buildings would be expensive, compliance with these criteria will likely involve the use of predictive methods. These predictive methods will be based on building ventilation and indoor air quality models such as the CONTAM multizone IAQ model developed in BFRL (Walton 1997). Before a CONTAM-based compliance approach can be incorporated into a performance standard, its predictive reliability must be demonstrated through experimental validation. While a number of studies have examined this issue (such as Herrlin 1992, GEOMET 1992, and Yuill and Upham 1997), there is a need to compile the information and perform further validation work - particularly in simulating the impact of IAQ control technologies.

Closely related to the issue of indoor environment performance standards is the issue of performance evaluation of specific indoor environment control technologies, such as residential ventilation systems and controls, air cleaning systems, humidity control technologies, and IAQ sensors. These potentially beneficial technologies have not gained wide acceptance in the 
marketplace, in part due to incomplete performance data from field tests or simulation studies. Therefore, validated predictive methods can be useful in evaluating the benefits and impacts of such technologies, both within the context of performance standards and potentially as a means of marketing and rating these technologies. Such performance evaluation is also needed to further develop these IAQ control technologies.

Therefore, to support development of performance standards and to begin demonstrating the ability of models to predict the impact of IAQ control technology, NIST has begun a project to validate CONTAM's predictive capability. The first effort in this project addressed the performance of particle air cleaners in a single-zone test house. This report describes this experimental validation effort with particle air cleaners.

\section{Literature Review}

Before starting the validation experiments, the literature was reviewed for information related to particles in residential buildings including air cleaner test standards, air cleaner test studies, and aerosol transport parameters. A comprehensive review of over 100 reports of particles in indoor air was recently published by Wallace (1996). This review concluded that indoor particle concentrations ranged from about the same as outdoor particle concentrations up to double the outdoor concentration. The major sources of particles inside homes and other buildings were identified as cigarette smoke, cooking, and outdoor particles. Cleaning activities and combustion appliances are smaller contributing sources, while a significant fraction comes from unidentified sources.

In the past, the most relevant test method for in-duct residential particulate air cleaners was ASHRAE Standard 52.1 (ASHRAE 1992), but this standard has several deficiencies that have been noted in the literature. For example, Hanley et al. (1994) points out that the weight arrestance test yields misleading results as it does not quantify results as a function of particle size and is biased by the large fraction by weight of larger, and easier to remove, particles. This and other deficiencies have led to a new ASHRAE Standard 52.2 "Method of Testing General Ventilation Air-Cleaning Devices for Removal Efficiency by Particle Size" that addresses this and other issues (ASHRAE 1999).

Another relevant test standard is the Association of Home Appliance Manufacturers (AHAM) Standard AC-1 for testing the performance of portable air cleaners (ANSI/AHAM 1988). This test method determines the performance of an air cleaner based on the decay rate of an elevated particle concentration in a test chamber. The air cleaner performance is expressed in terms of a Clean Air Delivery Rate (CADR) which is essentially the equivalent amount of particle-free ventilation air needed to achieve the same particle decay rate. Although not size-delineated, the test challenges an air cleaner with three different types of particles (cigarette smoke, Arizona road dust, and paper mulberry pollen) to yield three different CADR values. Although CADRs were not calculated, the method applied in this study resembled the AC-1 method in many aspects.

There have been several published reports of particle air cleaners for the residential market - most in the last decade. These include scientific studies of particle air cleaner performance in test chambers/houses (Offerman et al. 1985, Offerman et al. 1991, Hanley et al. 1994, and Bascom et 
al. 1996) and air cleaner tests in occupied homes (CMHC 1999, Burroughs and Kinzer 1998, Abraham 1999, Reisman et al. 1990, Swanson et al. 1985, Lofcoe and Inculet 1971, and Luczynska et al. 1990). A recent American Lung Association report summarizes many of these reports (ALA 1997). Among the reviewed reports is a recent article that rated 11 portable and 16 in-duct air cleaners (Consumer Reports 2000). The air cleaners were challenged with cigarette smoke and dust and evaluated for odor removal, cost, upkeep, and noise.

Two key particle-related parameters that impact indoor particle concentrations are particle deposition rates and penetration factors. Deposition can be a significant mechanism for removal of particles from indoor air through contact with room surfaces. It is typically accounted for as a first-order loss mechanism that is frequently treated as the product of a room surface-to-volume ratio and a deposition velocity. The particle penetration factor is the fraction of outdoor particles that enters an indoor space with infiltrating air as it moves through the building envelope.

A review of 66 publications on deposition rates and the use of deposition velocity was published by Nazaroff et al. (1993). This review found that, despite a sound theoretical concept and successful empirical application of the deposition method, caution is warranted in its application due to several limitations. These limitations include possible lack of uniform mixing, deposition may vary with location, first order rate assumption may be inadequate, and transport rates through boundary layers may depend on near-surface airflow conditions. The review reports a range of published deposition velocities for 'fine particles' from $2 \times 10^{-5} \mathrm{~cm} / \mathrm{s}$ to $5 \times 10^{-3} \mathrm{~cm} / \mathrm{s}$. Assuming a typical room surface-to-volume ratio of $3 \mathrm{~m}^{-1}$, the equivalent deposition rates would range from $7.2 \times 10^{-4} \mathrm{~h}^{-1}$ to $0.18 \mathrm{~h}^{-1}$. Other published measurements of deposition rates have included an average from 5 tests of $0.48 \mathrm{~h}^{-1}$ for fine particles from a gas-fired range in a test chamber (Traynor et al. 1982), average values of $0.39 \mathrm{~h}^{-1}$ for particles smaller than $2.5 \mu \mathrm{m}$ and $1.10 \mathrm{~h}^{-1}$ for particles between $2.5 \mu \mathrm{m}$ and $10.0 \mu \mathrm{m}$ from a study in 178 homes (Wallace 1996), average values in a residence of $0.46 \mathrm{~h}^{-1}$ for $1 \mu \mathrm{m}$ to $5 \mu \mathrm{m}$ particles and $1.36 \mathrm{~h}^{-1}$ for $5 \mu \mathrm{m}$ to 10 $\mu \mathrm{m}$ particles (Thatcher and Layton 1994), and mass-weighted average values for tobacco smoke particles of $0.05 \mathrm{~h}^{-1}$ and $0.1 \mathrm{~h}^{-1}$ in a research house (Offerman et al. 1985 and 1991).

Fewer measurements of penetration factors have been reported. One study reports penetration of 1 for various size particles in a single residence (Thatcher and Layton 1994), with another study also reporting 1 for all size particles in 178 homes (Wallace 1996). A value of 1 indicates no filtering of particles by the building envelope. One study reported a penetration of 0.4 for particles smaller than $0.5 \mu \mathrm{m}$ in an environmental chamber (Traynor et al. 1982). 


\section{Experimental Procedure}

Measurements of the performance of several particulate air cleaners and related particle transport parameters were performed in a one-room test house. These measurements were used to calculate building air change rates, particle deposition rates and penetration factors, and air cleaner removal efficiencies. Most of the tests consisted of the generation of particles indoors and the monitoring of the decay of the indoor particle concentration. Some parameters were determined by monitoring approximately steady state particle concentrations in the house. Two separate $24 \mathrm{~h}$ tests were then performed with two of the tested air cleaners, and the measured air change rates and particle concentrations were compared to corresponding simulations performed with the CONTAM model.

\section{Test House}

The initial phase tests were performed in a single-room test house located on the NIST campus (Burch et al. 1982). The test house has a floor area of $37 \mathrm{~m}^{2}\left(400 \mathrm{ft}^{2}\right)$ and a ceiling height of 2.3 $\mathrm{m}(7.5 \mathrm{ft})$. Its construction details include uninsulated wood-frame walls, paneled wood exterior, painted gypsum board interior, slab-on-grade foundation, unpainted concrete floors, vented attic and asphalt-shingled roof. The house also has two double-hung windows on the north and south walls and a metal exterior door filled with perlite insulation on the east wall. A fan pressurization test, performed according to American Society for Testing and Materials Standard E779-99 (ASTM 1999), found the building air change rate at $50 \mathrm{~Pa}$ to be $7.3 \mathrm{~h}^{-1}$ and the effective leakage area at $4 \mathrm{~Pa}$ to be $140 \mathrm{~cm}^{2}\left(21.1 \mathrm{in}^{2}\right)$. A schematic elevation and a floorplan of the house are shown in Figure 1 and Figure 2, respectively. The test house has a heating, ventilating and airconditioning (HVAC) system featuring a $4.1 \mathrm{~kW}(14,000 \mathrm{Btu} / \mathrm{h})$ electric-resistance furnace, a 3.8 $\mathrm{kW}(13,000 \mathrm{Btu} / \mathrm{h})$ air conditioner, and a nominal recirculation flow of $0.17 \mathrm{~m}^{3} / \mathrm{s}(360 \mathrm{cfm})$. As is typical for residences, the HVAC system has no outdoor air intake. A schematic of the system is shown in Figure 3.

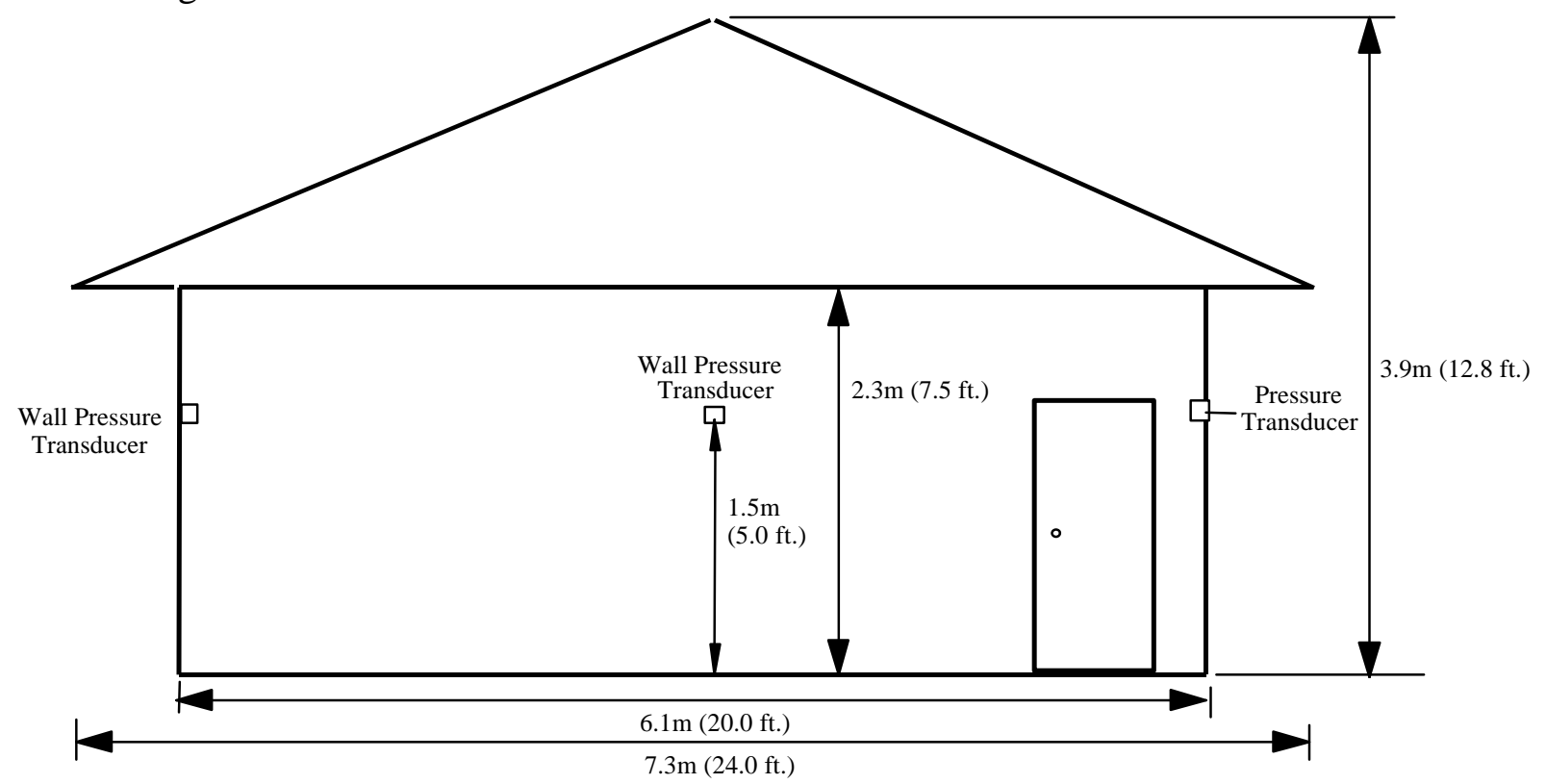

Figure 1 Schematic Elevation of Test House 


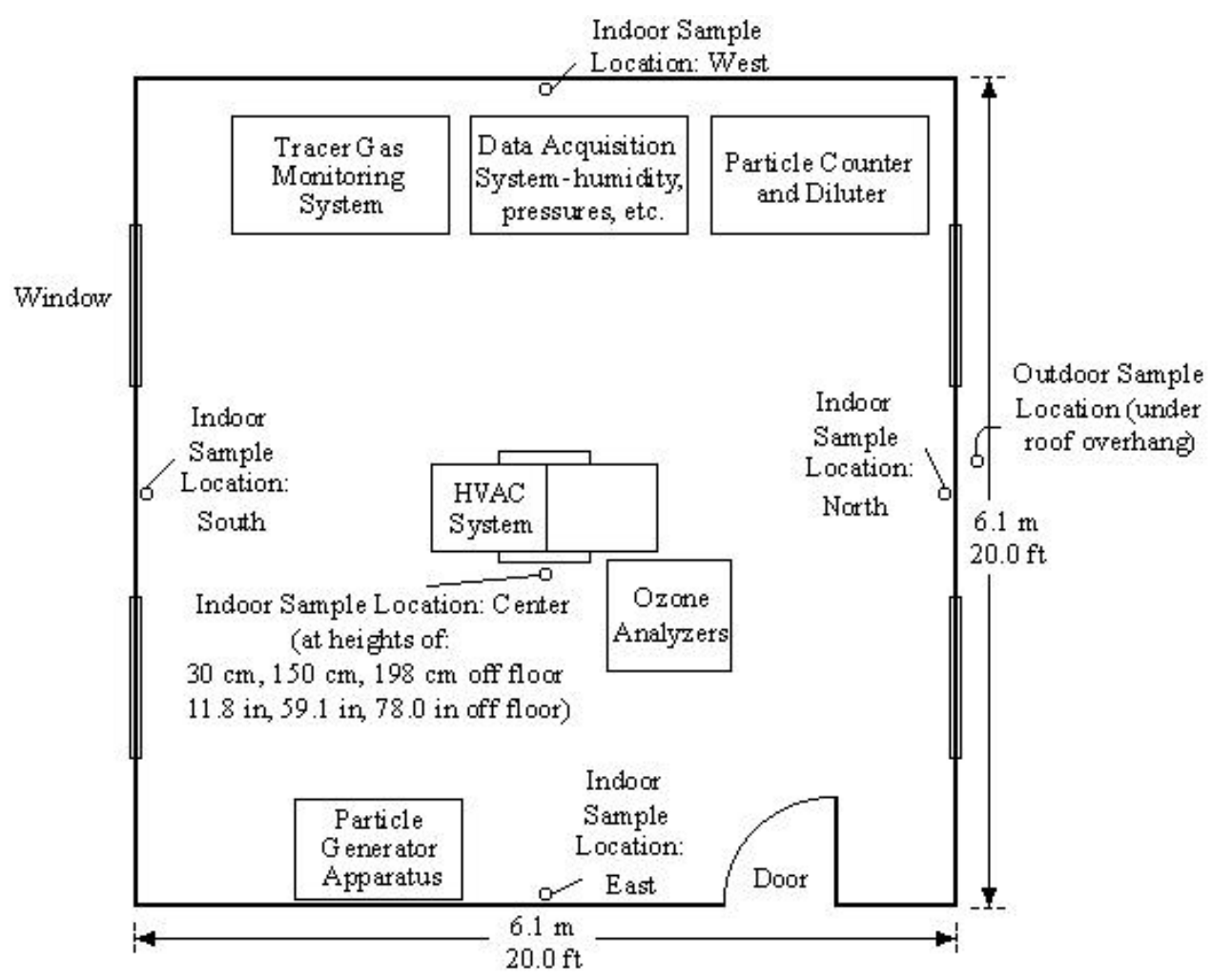

Figure 2 Schematic Floorplan of Test House

\section{Instrumentation}

\section{Sample Locations}

Figure 2 shows a schematic of the test house floorplan including instrumentation and sample locations. There were seven indoor sampling locations as follows: one location about $1.5 \mathrm{~m} \mathrm{(5 \textrm {ft } )}$

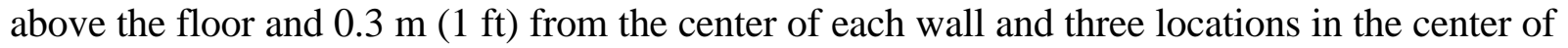
the room at heights of $0.3 \mathrm{~m}(1 \mathrm{ft}), 1.5 \mathrm{~m}(5 \mathrm{ft})$ and $2.0 \mathrm{~m}(6.6 \mathrm{ft})$ above the floor. Outdoor air samples were taken at a location sheltered by the eave of the roof, $2.1 \mathrm{~m}(6.9 \mathrm{ft})$ above the ground, $2.2 \mathrm{~m}(7.3 \mathrm{ft})$ from the west end of the north wall and $0.3 \mathrm{~m}(1 \mathrm{ft})$ from the wall. Particle counts were sampled at three locations in the HVAC duct including before the air cleaner, after the air cleaner, and after the standard furnace filter (see Figure 3).

\section{Infiltration}

The air change rate was measured using the tracer gas decay technique as described in ASTM Standard E741(ASTM 1995) with sulfur hexafluoride $\left(\mathrm{SF}_{6}\right)$ as the tracer gas. The automated air infiltration rate measurement system consists of a PC-based data acquisition and control system and a gas chromatograph (GC) with an electron capture detector (ECD). The system automatically injected $\mathrm{SF}_{6}$ into the house every $12 \mathrm{~h}$ to $24 \mathrm{~h}$. The GC-ECD was used to determine $\mathrm{SF}_{6}$ concentrations over a range of 5 parts per billion $(\mathrm{ppb}(\mathrm{v}))$ to $150 \mathrm{ppb}(\mathrm{v})$ with an accuracy of approximately $2 \%$. The tracer gas system uses a ten-port sample valve to sample air at seven indoor locations and one outdoor location every $10 \mathrm{~min}$. The hourly air change rate is then determined by performing a linear regression of the logarithm of the $\mathrm{SF}_{6}$ concentration versus time. The uncertainty of the measured air change rates is approximately $10 \%$. 

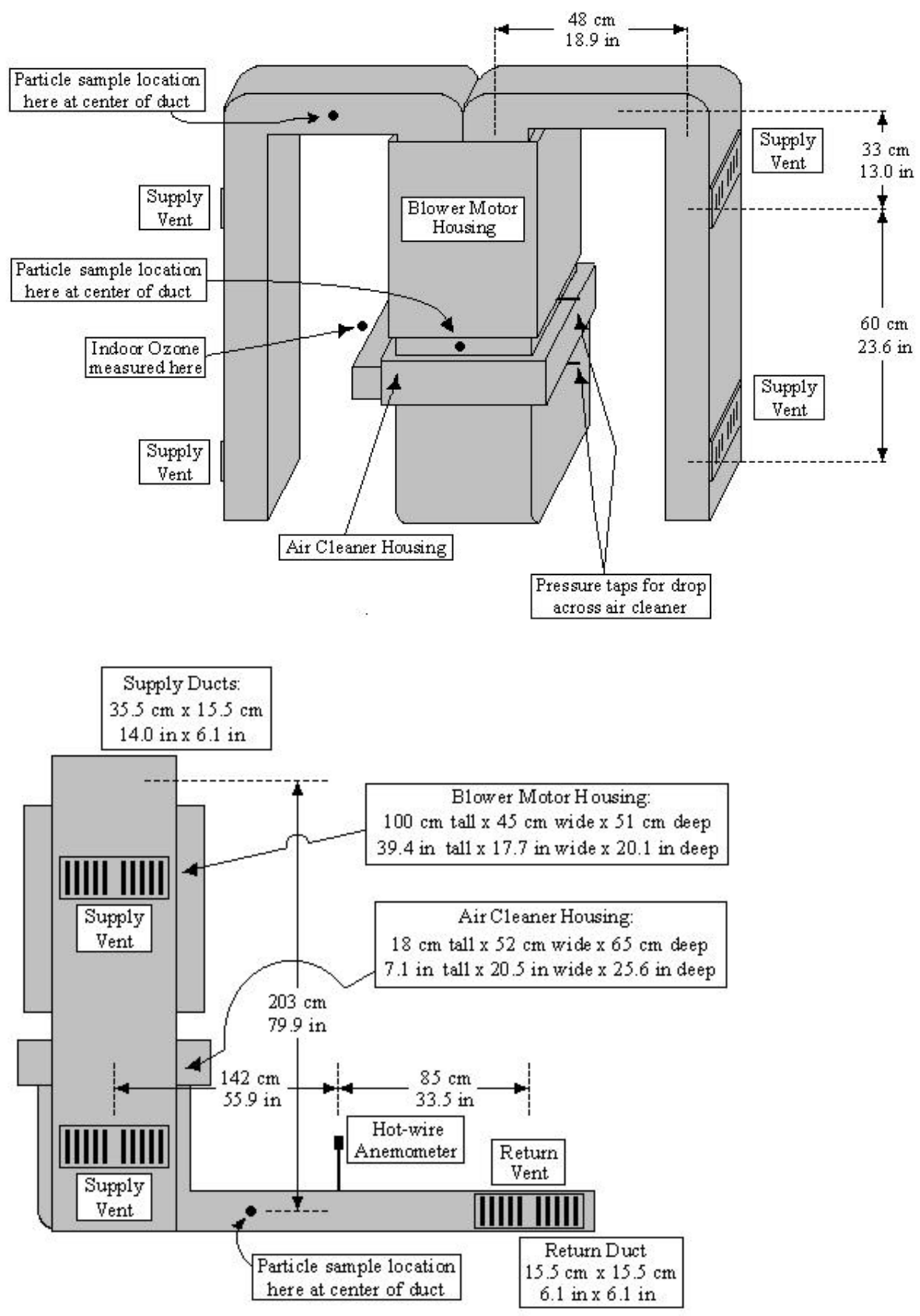

\section{Figure 3 Schematic of HVAC System (Front and Side Views)}

Particles

Airborne particle concentrations were measured with an optical particle counter utilizing a wide angle light scattering technique, calibrated by the manufacturer to a nominal accuracy of $20 \%$. It yields counts of particles in six size ranges: $0.3 \mu \mathrm{m}$ to $0.5 \mu \mathrm{m}, 0.5 \mu \mathrm{m}$ to $0.7 \mu \mathrm{m}, 0.7 \mu \mathrm{m}$ to 1.0 $\mu \mathrm{m}, 1.0 \mu \mathrm{m}$ to $5.0 \mu \mathrm{m}, 5.0 \mu \mathrm{m}$ to $10.0 \mu \mathrm{m}$, and $>10 \mu \mathrm{m}$. The particle counter was used in conjunction with a thirty-port sample valve to sample sequentially from all of the indoor, outdoor and HVAC duct locations. The particle counter has a controlled sample flow of $5 \times 10^{-4} \mathrm{~m}^{3} / \mathrm{s}(1$ $\mathrm{cfm})$ and a total concentration limit of $4.5 \times 10^{7}$ particles $/ \mathrm{m}^{3}\left(1.35 \times 10^{6}\right.$ particles $\left./ \mathrm{ft}^{3}\right)$. 
With the tube sampling system, there will be some unavoidable loss of particles within the sampling tubes due to physical processes including diffusion, settling, impaction, static attraction, and other loss factors. Sample losses were minimized by ensuring that the manufacturer's minimum flow rate was maintained through all tubes and minimizing the number of bends in the tube runs. Tests by the manufacturer estimated losses through a $15 \mathrm{~m} \mathrm{(50} \mathrm{ft)} \mathrm{sample} \mathrm{tube} \mathrm{were} 2$ $\%$ for $0.3 \mu \mathrm{m}$ to $0.5 \mu \mathrm{m}, 4 \%$ for $0.5 \mu \mathrm{m}$ to $1.0 \mu \mathrm{m}, 8 \%$ for $1.0 \mu \mathrm{m}$ to $5.0 \mu \mathrm{m}$, and $15 \%$ for $>5$

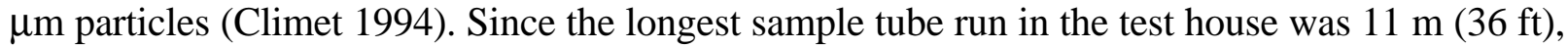
the potential particle loss was judged an acceptable trade-off for the better relative accuracy made possible by using a single counter for all indoor and outdoor locations.

Since the indoor and outdoor particle counts at times exceeded the counter limit, a particle diluter with a nominal dilution ratio of 100 to 1 was used during some of the tests. The diluter operated by diverting $99 \%$ of the sample flow through a zero filter and allowing $1 \%$ of the flow to pass through unfiltered. The actual dilution ratio was found to vary by size of the particles but was consistent over the duration of the individual tests performed. The variation in dilution by size ratio and from test to test has no significant impact on any of the parameters estimated from particle measurements. However, caution must be used in calculating actual particle counts by simply multiplying the values reported with the diluter by 100. Figure 4 shows the impact of the diluter on particle counts. Due to the use of the diluter, the already low concentrations of larger particles and the magnitude of sample tube losses, no useful data was obtained for the two size ranges larger than $5.0 \mu \mathrm{m}$.

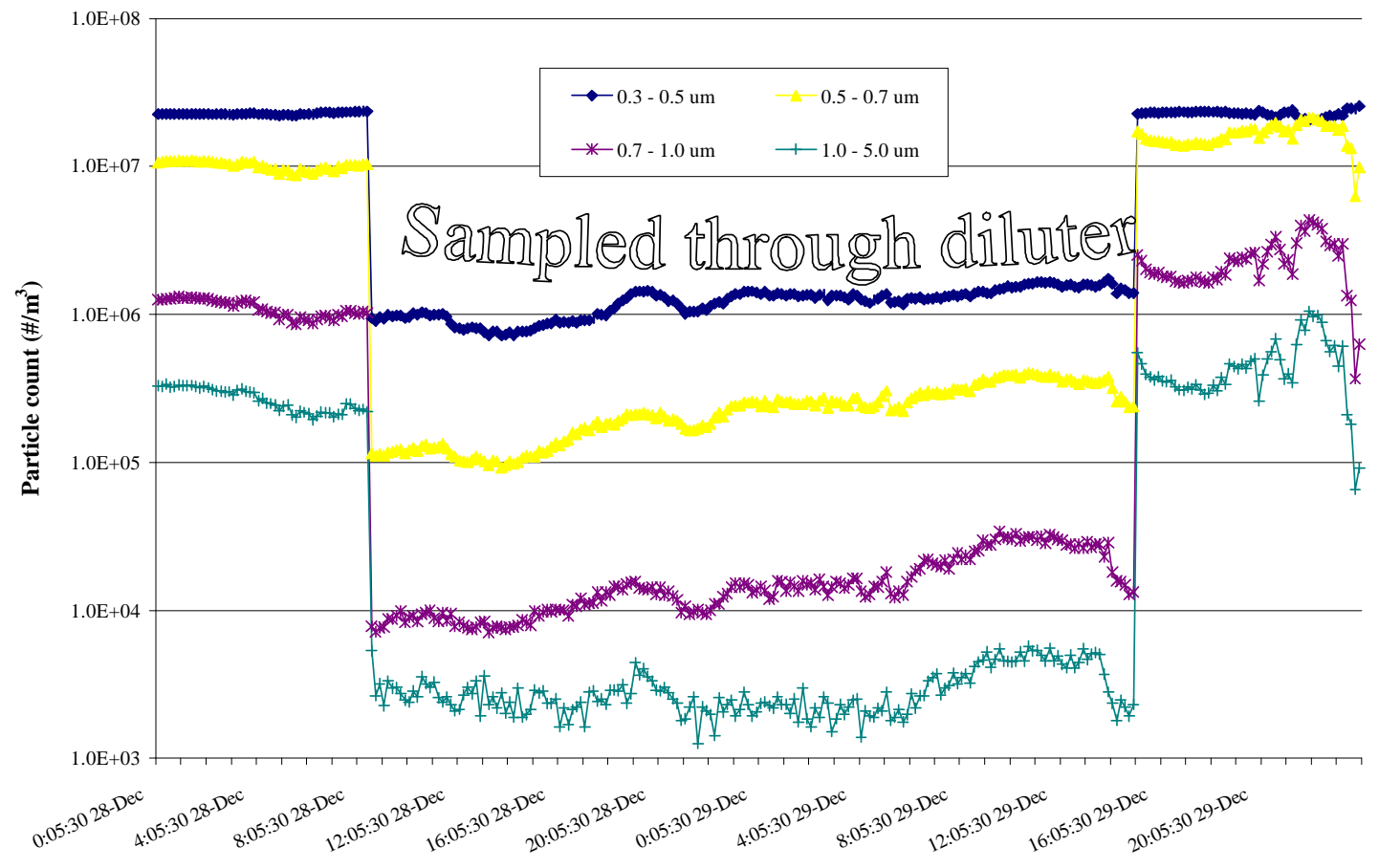

Figure 4 Outdoor Particle Counts Sampled with and without Diluter 
Other Parameters

Indoor and outdoor temperatures were measured with thermistors having an uncertainty of about $0.4^{\circ} \mathrm{C}\left(0.7^{\circ} \mathrm{F}\right)$. To measure wind speed and direction, an anemometer was installed on the west exterior wall about $2 \mathrm{~m}(6.6 \mathrm{ft})$ above the crest of the roof. Indoor and outdoor relative humidity was measured with bulk polymer resistance sensors with an accuracy of $3 \%$ of the reading. The pressure differences across the exterior walls were measured by differential pressure transducers located $1.5 \mathrm{~m}(6 \mathrm{ft})$ above the floor at the midpoint of each wall. The transducers have a range of $-25 \mathrm{~Pa}$ to $25 \mathrm{~Pa}$ (-0.1 in. to 0.1 in. of water) and an accuracy of $1 \%$ of full scale. A similar pressure transducer with a range of $-62.5 \mathrm{~Pa}$ to $62.5 \mathrm{~Pa}(-0.25 \mathrm{in}$. to $0.25 \mathrm{in}$. of water) was used to measure the pressure drop across the tested air cleaners.

Ozone was monitored to evaluate its generation as a side effect of electronic air cleaner operation. Indoor and outdoor ozone concentrations were measured with ultraviolet photometric ozone analyzers with a range of $0 \mathrm{ppm}(\mathrm{v})$ to $1.0 \mathrm{ppm}(\mathrm{v})$. The ozone meters were calibrated against an ozone standard generated by a calibration subsystem of one of the meters. This calibration yielded a $95 \%$ confidence interval for the meters of approximately $\pm 5 \mathrm{ppb}(\mathrm{v})$ over a measurement range of $5 \mathrm{ppb}(\mathrm{v})$ to $300 \mathrm{ppb}(\mathrm{v})$.

The airflow rate through the HVAC system was measured by initially performing a velocity traverse with a hot wire anemometer (HWA) to find a point representative of the average velocity in the return duct. The HWA has an uncertainty of $2.5 \%$ of the indicated reading. The measurements were performed in accordance ASHRAE Standard 111 (ASHRAE 1988) which is estimated to result in an uncertainty of $5 \%$ to $10 \%$ in field conditions. Then, another HWA was mounted at that point to measure an estimated average duct velocity during the individual tests.

An interesting observation was made on the quality of installation of the air cleaner by the HVAC contractor. A velocity traverse performed after the contractor completed the installation yielded an average flow velocity of $5.65 \mathrm{~m} / \mathrm{s}(18.6 \mathrm{ft} / \mathrm{s})$. After the research technician sealed the joint between the air cleaner and duct, two additional velocity traverses were performed with an overall average flow velocity of $6.42 \mathrm{~m} / \mathrm{s}(21.2 \mathrm{ft} / \mathrm{s})$. This indicates the importance of careful installation to avoid significant leakage around air cleaning systems that degrade overall system performance.

Many of the tests involved raising the indoor particle concentration, using either a particle generator or a manual technique, and then monitoring the decay of the concentration. The particle generator is a constant output atomizer that directs compressed air through a $0.343 \mathrm{~mm}(0.0137$ in) hole, forming a high velocity jet. A reservoir with a hydrosol consisting of polystyrene latex particles is supplied to the atomizing section of the particle generator. The high velocity jet draws the hydrosol by aspiration to create an aerosol that is mixed with air from a pump to disperse it within the test house. The polystyrene latex spheres used in the particle ranged in size from 0.36 $\mu \mathrm{m}$ to $1.53 \mu \mathrm{m}$. While very effective at generating high concentrations of the smaller particles, the particle generator was less effective at generating particles in the $1.0 \mu \mathrm{m}$ to $5.0 \mu \mathrm{m}$ size. For this reason, a manual technique was also used in some of the tests. This method consisted of pounding the test house floor with a large cardboard box and resulted in a strong spike in particle concentrations. 


\section{Air Cleaners}

A total of five different air cleaners were tested during the study. All of the air cleaners tested were installed in the HVAC system ductwork. Particle removal tests were also performed with no air cleaner in the HVAC system. Three of the air cleaners were mechanical filters, including a typical furnace filter (labeled MAC4 in test results) and two higher efficiency mechanical air cleaners (MAC1 and MAC3). MAC1 has nominal dimensions of $0.13 \mathrm{~m} \mathrm{x} 0.41 \mathrm{~m}$ x $0.61 \mathrm{~m} \mathrm{(5} \mathrm{in} \mathrm{x}$ 16 in $\times 24$ in) and a stated average arrestance of $93 \%$. Three different filter cartridges of the MAC1 type were tested and are labeled MAC1a, MAC1b, and MAC1c in the results. MAC3 has nominal dimensions of $0.025 \mathrm{~m} \times 0.41 \mathrm{~m} \mathrm{x} 0.64 \mathrm{~m}$ ( 1 in $\mathrm{x} 16$ in $\times 25$ in) and is described by the manufacturer as having electrostatically charged fibers that are more effective than ordinary fiberglass filters.

The remaining two air cleaners are electronic. The first electronic air cleaner (EAC1) is nominally $0.18 \mathrm{~m} \times 0.52 \mathrm{~m} \times 0.64 \mathrm{~m}(7-1 / 4$ in $\times 20-1 / 2$ in $\times 25$ in) and consists of ionizing wires at $6200 \mathrm{~V}$ that positively charge particle that are then deposited to ground collector plates. No quantified removal information is provided with EAC1 although the manual states that it will remove particles as small as $0.01 \mu \mathrm{m}$. EAC1 also has a mechanical prefilter that was tested separately. The manual also states that the unit will produce "minute" quantities of ozone and that the amount produced will be reduced after several weeks of operation. The second EAC (EAC2) is $0.0051 \mathrm{~m}$ thick and uses a $24 \mathrm{~V}$ source to create a polarized charge on two replaceable collecting pads. EAC2 is stated as having a particle removal efficiency ranging from $33 \%$ for $0.3 \mu \mathrm{m}$ particles up to $99 \%$ for $1.0 \mu \mathrm{m}$ particles and larger. EAC2 is claimed to produce no ozone. 


\section{EXPERIMENTAL RESULTS}

\section{Infiltration rates}

As described above, the test house air change rate was measured using the tracer gas decay technique as described in ASTM Standard E741(ASTM 1995) with an automated multiport SF $_{6}$ injection and measurement system. The $\mathrm{SF}_{6}$ concentration was measured every 10 min at 9 locations in the test house. The test house air change rate is then determined by performing a linear regression of the logarithm of the concentration versus time for individual one hour periods. Test house infiltration rates under a range of indoor-outdoor temperature differences and wind speeds are shown in Figures 5 and 6, respectively. As expected, Figure 5 shows a minimum infiltration rate at $T_{\text {in }}-T_{\text {out }}=0$ and increasing infiltration with increasing $\left|T_{\text {in }}-T_{\text {out }}\right|$, and Figure 6 shows increasing infiltration with increasing wind speed.

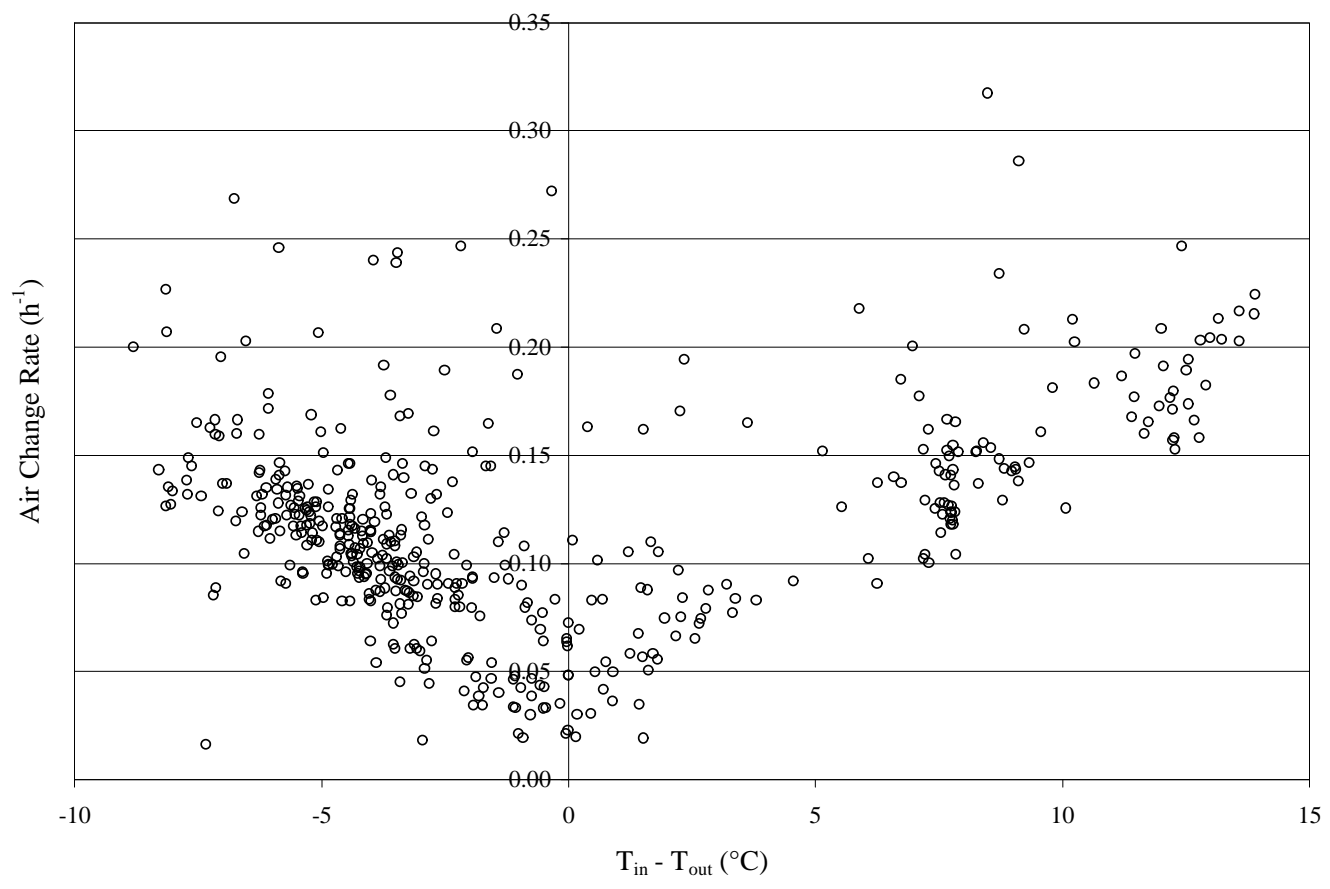

Figure 5 Measured Hourly Infiltration Rates (Wind Speed $<0.5$ m/s) 


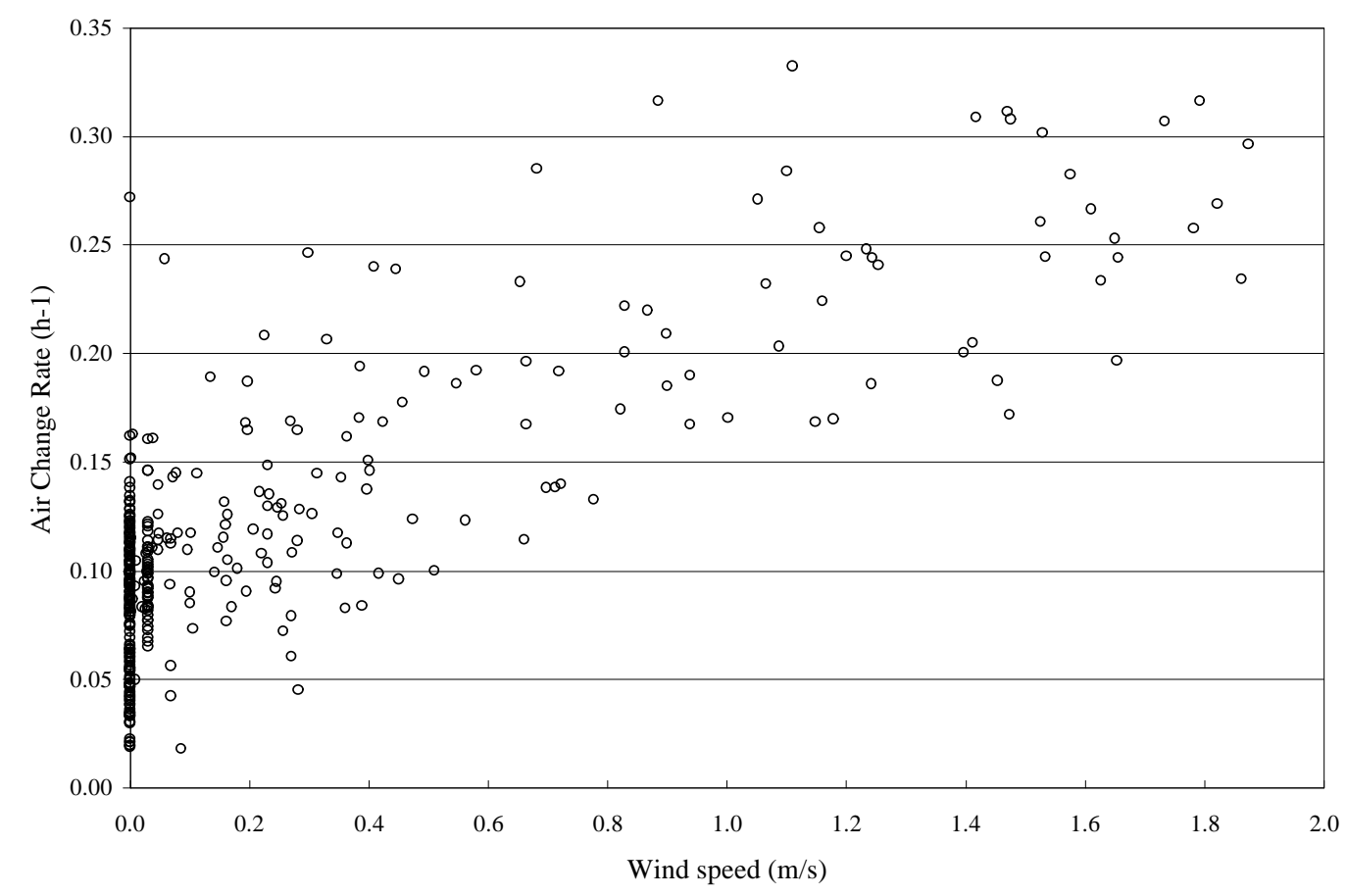

Figure 6 Measured Hourly Infiltration Rates $\left(\left|\mathbf{T}_{\text {in }}-\mathbf{T}_{\text {out }}\right|<5^{\circ} \mathbf{C}\right)$

\section{Deposition rates}

Particle deposition rates in the test house were determined both for use in the CONTAM model and for the analysis of filtration efficiencies. The analysis of deposition rates is very similar to a tracer gas decay test except for the need to account for the penetration of particles from outside. Assuming uniform particle concentrations in the test house, the mass balance equation for the indoor particle concentration is:

$\frac{d C_{\text {in }}}{d t}=a P C_{\text {out }}+\frac{S}{V}-k^{*} C_{\text {in }}$

To evaluate the validity of the uniform particle concentration assumption, samples were taken at the seven interior locations discussed earlier. Figure 7 presents an example of the concentration uniformity in the house for one hour prior to turning the particle generator off for test case $\mathrm{d} 74$ during which the HVAC system fan is off. 


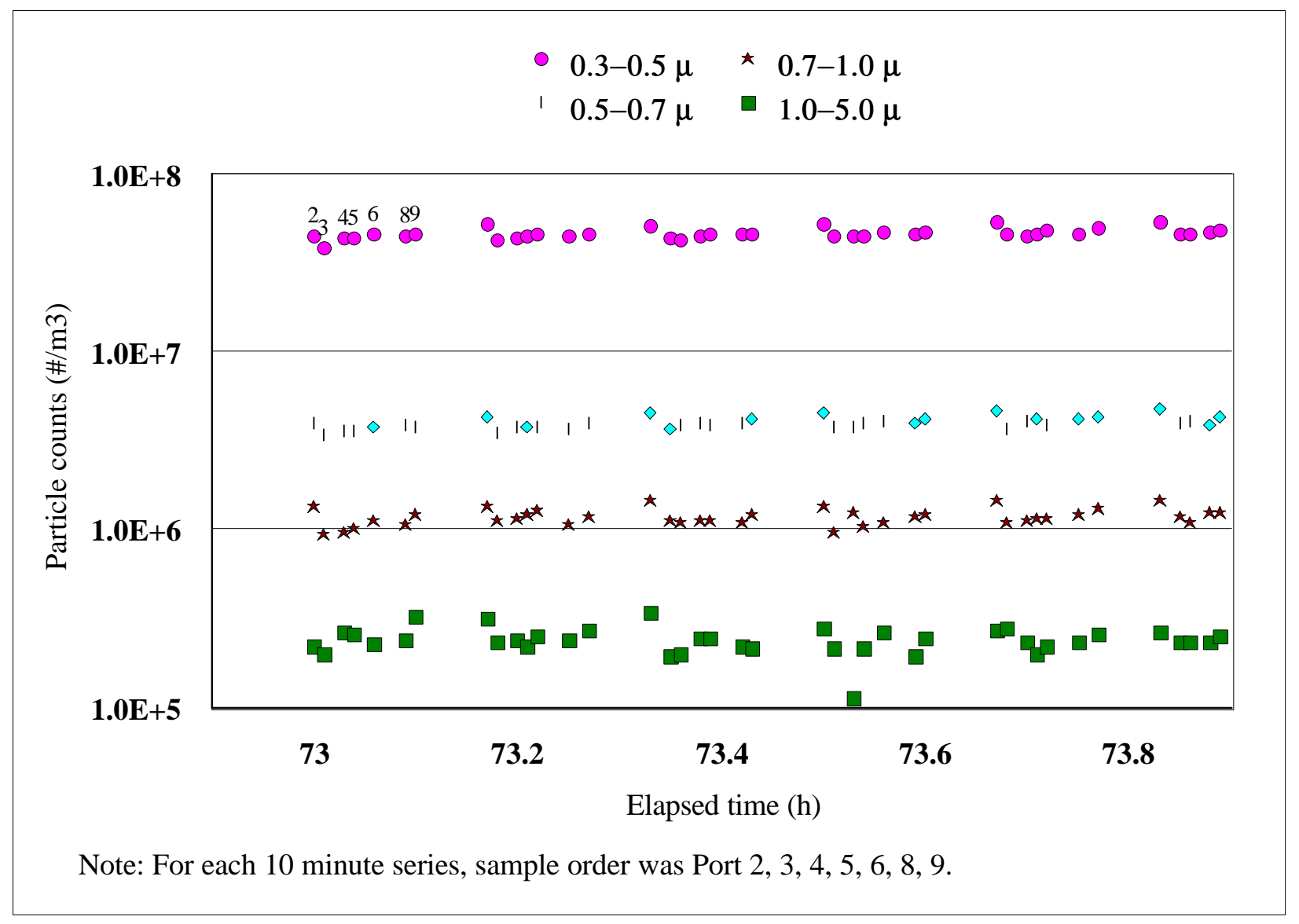

Figure 7 - Mixing in test house for case d74

Assuming there is no indoor source $(\mathrm{S})$ and that the outdoor particle concentration $\left(\mathrm{C}_{\text {out }}\right)$, the air change rate $(\mathrm{a})$, the penetration factor $(\mathrm{P})$, and the total decay rate $\left(\mathrm{k}^{*}\right)$ are all constant, the solution to this linear, first order differential equation with arbitrary constant $\left(\mathrm{C}_{1}\right)$ is:

$$
C_{\text {in }}(t)=\frac{a P C_{\text {out }}}{k^{*}}+C_{1} e^{-k^{*} t}
$$

Thus, $\mathrm{k}^{*}$ can then be determined by performing a linear regression of the logarithm of the indoor concentration minus $\mathrm{aPC}_{\text {out }} / \mathrm{k}^{*}$ versus time. Since $\mathrm{k}^{*}$ appears in the expression to be subtracted from the concentration, it was necessary to solve the linear regression through an iterative process. The penetration factor was assumed to be one (i.e. no filtration of particles on entry to building). For selected cases, the penetration factor was varied within the range of 0.5 to 1.0 with no significant effect on the decay rates. This decay analysis was applied to one hour of data following the particle generation and was performed with the HVAC system off and with the HVAC system on but no air cleaner in the system. Table 1 summarizes the total decay results for five cases with the system off and nine cases with the system on. 
Table 1 Summary of Total Decay Rates for Deposition Cases

\begin{tabular}{|c|c|c|c|c|c|c|c|c|c|c|c|}
\hline $\begin{array}{l}\text { Run } \\
\text { No. }\end{array}$ & \begin{tabular}{|c|} 
Particle \\
Generation \\
Method
\end{tabular} & \begin{tabular}{|c|} 
Duct \\
Velocity \\
$(\mathrm{m} / \mathrm{s})$
\end{tabular} & $\begin{array}{c}\text { Air Change } \\
\text { Rate } \\
\left(\mathrm{h}^{-1}\right)\end{array}$ & $\begin{array}{c}\text { Decay } \\
.3-.5 \mu \mathrm{m} \\
\left(\mathrm{h}^{-1}\right)\end{array}$ & $\begin{array}{c}\text { Decay } \\
.5-.7 \mu \mathrm{m} \\
\left(\mathrm{h}^{-1}\right)\end{array}$ & $\begin{array}{c}\text { Decay } \\
.7-1.0 \mu \mathrm{m} \\
\left(\mathrm{h}^{-1}\right)\end{array}$ & \begin{tabular}{|c} 
Decay \\
$1.0-5.0 \mu \mathrm{m}$ \\
$\left(\mathrm{h}^{-1}\right)$
\end{tabular} & $\begin{array}{c}\mathbf{T}_{\mathrm{in}} \\
\left({ }^{\circ} \mathbf{C}\right)\end{array}$ & $\begin{array}{l}\mathbf{T}_{\text {out }} \\
\left({ }^{\circ} \mathbf{C}\right)\end{array}$ & $\begin{array}{c}\mathbf{R H}_{\text {in }} \\
(\%)\end{array}$ & $\begin{array}{c}\mathbf{R H}_{\text {ou }} \\
\mathrm{t} \\
(\%)\end{array}$ \\
\hline$\overline{d 51 x}$ & PGEN & off & 0.16 & 0.40 & 0.57 & 0.62 & 0.86 & 33.1 & 25.2 & 45 & 84 \\
\hline d71x & PGEN & off & 0.21 & 0.60 & 0.90 & 1.00 & 1.06 & 27.6 & 11.7 & 32 & 29 \\
\hline d74x & PGEN & off & 0.22 & 0.73 & 0.93 & 1.01 & 1.44 & 25.2 & 14.3 & 27 & 39 \\
\hline d75x & BOX & off & 0.22 & 0.50 & 0.81 & 1.06 & 1.43 & 24.9 & 11.0 & 27 & 24 \\
\hline d76x & BOX & off & 0.24 & 0.53 & 0.85 & 1.10 & 1.43 & 23.3 & 11.4 & 26 & 44 \\
\hline d40x & PGEN & 5.73 & 0.12 & 0.76 & 1.01 & 1.67 & 2.31 & 31.0 & 32.4 & 27 & 43 \\
\hline d61x & PGEN & 5.92 & 0.15 & 0.95 & 1.24 & 1.48 & 2.09 & 21.0 & 19.8 & 47 & 62 \\
\hline$d 62 x$ & PGEN & 5.83 & 0.14 & 0.96 & 1.24 & 1.49 & 2.15 & 20.8 & 20.3 & 41 & 68 \\
\hline d66x & PGEN & 5.89 & 0.28 & 1.08 & 1.35 & 1.65 & 1.99 & 19.7 & 5.9 & 36 & 55 \\
\hline d67x & PGEN & 5.83 & 0.20 & 0.98 & 1.29 & 1.60 & 1.79 & 20.3 & 5.7 & 39 & 48 \\
\hline d79x & BOX & 5.90 & 0.20 & 0.98 & 1.47 & 1.85 & 2.24 & 19.7 & 16.0 & 31 & 25 \\
\hline a12x & BOX & 5.83 & 0.49 & 1.14 & 1.67 & 2.06 & 2.72 & 25.1 & 17.2 & 30 & 33 \\
\hline a12x & BOX & 5.79 & 0.31 & 0.94 & 1.61 & 2.03 & 2.64 & 19.1 & 19.0 & 36 & 39 \\
\hline a12x & BOX & 5.77 & 0.17 & 0.90 & 1.32 & 1.73 & 2.34 & 18.3 & 13.1 & 39 & 51 \\
\hline
\end{tabular}

The deposition rate to the room surfaces can be obtained by subtracting the removal due to infiltration from the total decay. The total decay rates in Table 1 include other removal processes such as coagulation. However, for a test on the order of one hour, coagulation will be negligible for any particle concentration less than $10^{12} \mathrm{~m}^{-3}$ (Figure 12.3 of Hinds 1982). Since the particle concentration in the test house is less than $10^{9} \mathrm{~m}^{-3}$ for all cases, coagulation will be neglected in this analysis. The average deposition rates for both the HVAC system on and off, and the corresponding standard deviations, are presented in Table 2. For all four size ranges, the deposition rate was about double with the system on vs. system off. However, it was not determined whether this increase was due primarily to increased deposition to room surfaces or deposition within the HVAC system itself.

Table 2 Average Deposition Rates with HVAC System On and Off

\begin{tabular}{|l|c|c|c|c|}
\hline & $\begin{array}{c}\text { Deposition } \\
\mathbf{. 3 - 5 \mu \mathrm { m }} \\
\left(\mathbf{h}^{-1}\right)\end{array}$ & $\begin{array}{c}\text { Deposition } \\
\mathbf{. 5 - 7 \mu \mathrm { m }} \\
\left(\mathbf{h}^{-1}\right)\end{array}$ & $\begin{array}{c}\text { Deposition } \\
\mathbf{7 - 1 . 0 \mu \mathrm { m }} \\
\left(\mathbf{h}^{-1}\right)\end{array}$ & $\begin{array}{c}\text { Deposition } \\
\mathbf{1 . 0 - 5 . 0 \mu \mathrm { m }} \\
\left(\mathbf{h}^{-1}\right)\end{array}$ \\
\hline System off & & & & \\
Mean & 0.34 & 0.60 & 0.75 & 1.03 \\
$\boldsymbol{\sigma}$ & 0.11 & 0.12 & 0.16 & 0.24 \\
\hline System on & & & & \\
Mean & 0.74 & 1.13 & 1.50 & 2.02 \\
$\boldsymbol{\sigma}$ & 0.08 & 0.12 & 0.14 & 0.24 \\
\hline
\end{tabular}

\section{Penetration factors}

Penetration factors for the various particle sizes were determined from steady state particle concentration data. At steady state (and replacing $\mathrm{k}^{*}$ with $\mathrm{a}+\mathrm{k}$ ), equation 2 becomes:

$P=\frac{(a+k) C_{\text {in }}}{a C_{\text {out }}}$ 
The penetration factors were determined during tests with the HVAC system off so the values used for the deposition rates are the system-off values in Table 2. Table 3 summarizes the results of penetration factor calculations for five time periods of at least 1 hour during which the standard deviation of both $\mathrm{C}_{\mathrm{in}}$ and $\mathrm{C}_{\text {out }}$ were less than $10 \%$ of the average value (with the exception of the $1.0 \mu \mathrm{m}$ to $5.0 \mu \mathrm{m}$ size for case d75_2). Other criteria for the time periods included in Table 3 included the use of data measured without the diluter and a total outdoor count less than $2.5 \times 10^{6}$ particles per $\mathrm{m}^{3}$. The estimates for the smallest particles varied widely with an overall standard deviation that was over $35 \%$ of the average of 0.76 . The standard deviations for the larger sizes were all less than or equal to $20 \%$ of the averages. However, since only five cases are included in Table 3, these should be used with caution and may not apply to other buildings.

Table 3 Penetration Factors

\begin{tabular}{|l|c|c|c|c|}
\hline & $\mathbf{P}$ & $\mathbf{P}$ & $\mathbf{P}$ & $\mathbf{P}$ \\
& $\mathbf{. 3 - . 5 \mu \mathbf { m }}$ & $\mathbf{. 5 - . 7 \mu \mathbf { m }}$ & $\mathbf{. 7 - 1 . 0} \mu \mathbf{m}$ & $\mathbf{1 . 0 - 5 . 0 \mu \mathbf { m }}$ \\
\hline $\mathrm{d} 75$ & 0.67 & 0.74 & 0.67 & 0.61 \\
\hline $\mathrm{d} 75 \_2$ & 0.88 & 0.88 & 0.77 & 0.46 \\
\hline $\mathrm{d} 75 \_3$ & 0.82 & 0.78 & 0.68 & 0.69 \\
\hline $\mathrm{d} 76$ & 1.08 & 0.79 & 0.63 & 0.64 \\
\hline $\mathrm{d} 76 \_3$ & 0.35 & 0.49 & 0.55 & 0.59 \\
\hline Average & $\mathbf{0 . 7 6}$ & $\mathbf{0 . 7 3}$ & $\mathbf{0 . 6 6}$ & $\mathbf{0 . 6 0}$ \\
\hline $\boldsymbol{\sigma}$ & $\mathbf{0 . 2 7}$ & $\mathbf{0 . 1 5}$ & $\mathbf{0 . 0 8}$ & $\mathbf{0 . 0 9}$ \\
\hline
\end{tabular}

Filtration efficiencies from decay tests

The decay tests to determine the filtration efficiencies of the tested air cleaners were performed in a manner similar to those described above for determining deposition rates. After the indoor generation of particles, the HVAC system with the air cleaner installed was turned on and the decay of particle concentration was monitored. The total decay rate $\left(\mathrm{k}^{*}\right)$ for these tests was determined according to equation 2 above with the same assumptions of a uniform indoor particle concentration, no indoor source of particles, and constant $\mathrm{C}_{\text {out }}, \mathrm{a}, \mathrm{P}$, and $\mathrm{k}^{*}$. Due to the rapid decay of particle concentrations for the electronic air cleaner EAC1, the decay rate was determined over 30 minutes instead of one hour. Table 4 summarizes the total decay rates for the air cleaner tests. 
Table 4 Summary of Total Decay Rates for Air Cleaner Cases

\begin{tabular}{|c|c|c|c|c|c|c|c|c|c|c|c|}
\hline $\begin{array}{l}\text { Run } \\
\text { No. }\end{array}$ & $\begin{array}{c}\text { Air } \\
\text { Cleaner }\end{array}$ & $\begin{array}{c}\text { Particle } \\
\text { Generation } \\
\text { Method }\end{array}$ & $\begin{array}{c}\text { Duct } \\
\text { Velocity } \\
(\mathbf{m} / \mathbf{s})\end{array}$ & $\begin{array}{c}\text { Air } \\
\text { change } \\
\text { rate }\left(h^{-1}\right)\end{array}$ & $\begin{array}{c}\text { Decay } \\
.3-.5 \mu \mathrm{m} \\
\left(\mathrm{h}^{-1}\right)\end{array}$ & $\begin{array}{c}\text { Decay } \\
.5-.7 \mu \mathrm{m} \\
\left(\mathrm{h}^{-1}\right)\end{array}$ & $\begin{array}{c}\text { Decay } \\
.7-1.0 \mu \mathrm{m} \\
\left(\mathbf{h}^{-1}\right)\end{array}$ & $\begin{array}{c}\text { Decay } \\
1.0-5.0 \mu \mathrm{m} \\
\left(\mathrm{h}^{-1}\right)\end{array}$ & $\begin{array}{c}\mathbf{T}_{\text {in }} \\
\left({ }^{\circ} \mathbf{C}\right)\end{array}$ & $\begin{array}{c}\mathrm{RH}_{\text {in }} \\
(\%)\end{array}$ & $\begin{array}{c}\Delta \mathbf{P} \text { across } \\
\text { air } \\
\text { cleaner } \\
(\mathbf{P a}) \\
\end{array}$ \\
\hline d42x* & MAC1a & PGEN & 6.44 & 0.13 & 1.00 & 1.30 & 1.70 & 2.16 & 22.3 & 34 & 3.0 \\
\hline$d 44 x^{*}$ & MAC1a & PGEN & 6.33 & 0.14 & 1.04 & 1.47 & 1.87 & 2.74 & 22.4 & 33 & 3.6 \\
\hline d46x & MAC1a & PGEN & 6.34 & 0.29 & 1.09 & 1.50 & 2.02 & 2.83 & 28.5 & 28 & 2.5 \\
\hline d68x* & MAC1a & PGEN & 5.96 & 0.37 & 1.33 & 1.53 & 1.85 & 2.42 & 22.1 & 29 & 2.8 \\
\hline$d 77 x$ & MAC1a & BOX & 5.99 & 0.12 & 0.93 & 1.57 & 2.05 & 2.47 & \begin{tabular}{|l|}
19.4 \\
\end{tabular} & 34 & 3.2 \\
\hline$d 77 x$ & MAC1a & BOX & 5.96 & 0.13 & 0.86 & 1.58 & 2.11 & 2.80 & \begin{tabular}{|l|}
19.8 \\
\end{tabular} & 30 & 3.2 \\
\hline d59x & MAC1b & PGEN & 5.83 & 0.21 & 1.23 & 1.53 & 1.72 & 2.54 & 24.8 & 28 & 2.9 \\
\hline d60x & MAC1b & PGEN & 5.94 & 0.15 & 1.09 & 1.35 & 1.64 & 2.08 & 21.5 & 31 & 3.2 \\
\hline d68x & MAC1b & PGEN & 5.98 & 0.29 & 1.20 & 1.50 & 1.88 & 2.05 & 20.8 & 30 & 3.6 \\
\hline d68x & MAC1b & PGEN & 5.94 & 0.28 & 1.38 & 1.71 & 2.15 & 2.38 & 22.0 & 31 & 3.1 \\
\hline d72x & MAC1b & PGEN & 6.10 & 0.33 & 1.39 & 1.85 & 2.26 & 2.72 & 22.6 & 30 & 3.1 \\
\hline d81x & MAC1b & BOX & 6.04 & 0.20 & 0.94 & 1.50 & 1.94 & 2.60 & 22.3 & 34 & 3.7 \\
\hline d86 & MAC1c & BOX & 5.83 & 0.15 & 0.15 & 0.96 & 1.50 & 1.93 & 23.5 & 31 & 3.3 \\
\hline d86 & MAC1c & BOX & 5.75 & 0.15 & 0.15 & 0.96 & 1.55 & 2.00 & 22.3 & 35 & 3.3 \\
\hline a01 & MAC1c & BOX & 5.67 & 0.18 & 0.19 & 1.44 & 1.96 & 2.18 & 19.7 & 34 & 3.4 \\
\hline a01 & MAC1c & BOX & 5.64 & 0.24 & 0.24 & 1.43 & 2.09 & 2.20 & 19.2 & 38 & 3.5 \\
\hline a02 & MAC1c & BOX & 5.76 & 0.15 & 0.15 & 0.83 & 1.53 & 2.03 & 21.2 & 36 & 3.4 \\
\hline a02 & MAC1c & BOX & 5.68 & 0.23 & 0.23 & 0.89 & 2.02 & 2.52 & 24.6 & 36 & 3.2 \\
\hline a04 & MAC1c & BOX & 5.83 & 0.25 & 0.25 & 1.00 & 1.57 & 1.98 & 21.5 & 27 & 3.2 \\
\hline a04 & MAC1c & BOX & 5.78 & 0.38 & 0.38 & 1.14 & 1.71 & 2.18 & 24.3 & 26 & 3.4 \\
\hline$d 47 x$ & MAC3 & PGEN & 6.09 & 0.30 & 2.84 & 3.32 & 3.69 & 3.95 & 28.5 & 30 & 7.6 \\
\hline d47x & MAC3 & PGEN & 6.14 & 0.23 & 2.93 & 3.45 & 4.24 & 5.37 & 24.4 & 33 & 7.4 \\
\hline$d 48 x$ & MAC3 & PGEN & 6.07 & 0.23 & 2.89 & 3.34 & 4.03 & 4.33 & 29.9 & 30 & 6.8 \\
\hline d80x & MAC3 & BOX & 5.57 & 0.15 & 2.32 & 3.30 & 4.04 & 5.12 & \begin{tabular}{|l|}
19.3 \\
\end{tabular} & 32 & 6.3 \\
\hline d80x & MAC3 & BOX & 5.66 & 0.10 & 2.12 & 3.34 & 4.16 & 5.35 & 18.6 & 44 & 6.4 \\
\hline $\mathrm{d} 82 x$ & MAC4 & BOX & 5.61 & 0.31 & 1.22 & 1.63 & 1.93 & 2.23 & \begin{tabular}{|l|}
21.7 \\
\end{tabular} & 25 & $* *$ \\
\hline d82x & MAC4 & BOX & 5.47 & 0.32 & 1.10 & 1.50 & 1.86 & 2.39 & 25.3 & 24 & $* *$ \\
\hline d82x & MAC4 & BOX & 5.45 & 0.20 & 0.77 & 1.36 & 1.81 & 2.49 & 22.3 & 28 & $* *$ \\
\hline d55x $x^{t}$ & EAC1 & PGEN & 6.02 & 0.16 & 6.64 & 6.77 & 7.16 & 8.18 & 26.5 & 30 & 0.6 \\
\hline $\mathrm{d56}^{\mathrm{t}}$ & EAC1 & PGEN & 6.13 & 0.18 & 7.26 & 7.25 & 7.11 & 7.85 & \begin{tabular}{|l|}
24.7 \\
\end{tabular} & 33 & 1.3 \\
\hline d56 $x^{t}$ & EAC1 & PGEN & 6.06 & 0.14 & 6.49 & 6.68 & 7.20 & 7.81 & 28.8 & 28 & 1.2 \\
\hline d56 $x^{t}$ & EAC1 & PGEN & 6.15 & 0.12 & 6.44 & 6.70 & 7.14 & 7.87 & \begin{tabular}{|l|}
27.5 \\
\end{tabular} & 28 & 1.2 \\
\hline d56 $x^{t}$ & EAC1 & PGEN & 6.18 & 0.22 & 6.78 & 7.06 & 6.81 & 8.21 & 26.1 & 31 & 1.2 \\
\hline d56 $x^{t}$ & EAC1 & PGEN & 6.14 & 0.22 & 6.72 & 6.83 & 7.15 & 7.90 & \begin{tabular}{|l|}
21.8 \\
\end{tabular} & 33 & 1.3 \\
\hline $\mathrm{d}^{28 x^{t}}$ & EAC1 & BOX & 5.84 & 0.35 & 5.19 & 6.45 & 6.85 & 7.70 & \begin{tabular}{|l|}
19.8 \\
\end{tabular} & 33 & 1.4 \\
\hline $\mathrm{d}^{28 x^{t}}$ & EAC1 & BOX & 5.88 & 0.33 & 5.84 & 6.77 & 7.14 & 8.04 & \begin{tabular}{|l|}
20.0 \\
\end{tabular} & 30 & 1.4 \\
\hline d58x & EAC2 & PGEN & 5.05 & 0.10 & 1.17 & 1.51 & 2.00 & 2.54 & \begin{tabular}{|l|}
21.7 \\
\end{tabular} & 43 & $* * *$ \\
\hline d58x* & EAC2 & PGEN & 4.86 & 0.12 & 1.14 & 1.48 & 1.80 & 2.59 & \begin{tabular}{|l|}
25.9 \\
\end{tabular} & 29 & $* * *$ \\
\hline d81x & EAC2 & BOX & 4.81 & 0.16 & 1.38 & 2.12 & 2.49 & 3.26 & \begin{tabular}{|l|l|}
18.6 \\
\end{tabular} & 46 & $* * *$ \\
\hline$d 81 x^{t t}$ & EAC2 & BOX & 4.80 & 0.17 & 1.35 & 2.03 & 2.42 & 3.11 & 18.6 & 50 & $* * *$ \\
\hline
\end{tabular}


Table 4 Notes: *Total decay rate for large particles based on less than $1 \mathrm{hr}$

** No $\triangle \mathrm{P}$ available across MAC4 due to filter location

*** No $\triangle \mathrm{P}$ available across EAC2 due to modified air cleaner frame

${ }^{\mathrm{t}}$ Total decay rates for EAC1 based on half hour

${ }^{t t}$ Air change rate calculated for 50 minutes

Subtracting the air change rate and the deposition to the surfaces from the total removal rates of Table 3 yields the removal rate due to the air cleaner $\left(k_{a c}\right)$. The filtration efficiency $(\eta)$ is calculated from the removal rate due to the air cleaner using the following equation:

$k_{a c}=\frac{Q_{s y s} \eta}{V}$

where $\mathrm{Q}_{\text {sys }}$ is the airflow rate through the HVAC system and V is the room volume.

Since it is not known whether the increased deposition rate for the system on cases is due to increased deposition to room surfaces or removal within the HVAC system and ductwork, two options for modeling the removal of particles due to the air cleaner and deposition were explored. First, the air cleaner efficiencies were calculated by subtracting the deposition with the system off (values from Table 2) from the total decay rates. This method includes the additional removal as part of the filtration efficiency. These average air cleaner efficiencies and their standard deviations are presented in Table 5. Also included in Table 5 are the decay results for HVAC system operation with no air cleaner in the system (labeled none in table) calculated as a filtration efficiency. The total decay rates for these no air cleaner cases was presented earlier as the bottom nine cases in Table 1.

Table 5 Decay Test Filter Efficiencies (Subtracting System-Off Deposition)

\begin{tabular}{|c|c|c|c|c|}
\hline Air Cleaner & $\begin{array}{c}\eta \\
.3-.5 \mu \mathrm{m} \\
(\%) \\
\end{array}$ & $\begin{array}{c}\eta \\
.5-.7 \mu \mathrm{m} \\
(\%) \\
\end{array}$ & $\begin{array}{c}\eta \\
.7-1.0 \mu \mathrm{m} \\
(\%) \\
\end{array}$ & $\begin{array}{c}\eta \\
1.0-5.0 \mu \mathrm{m} \\
(\%) \\
\end{array}$ \\
\hline none & 6.9 & 9.2 & 13.1 & 17.3 \\
\hline$\sigma$ & 1.3 & 2.1 & 2.5 & 4.3 \\
\hline MAC1a & 8.3 & 11.5 & 16.4 & 22.1 \\
\hline$\sigma$ & 1.4 & 2.5 & 3.5 & 4.7 \\
\hline MAC1b & 10.6 & 12.4 & 16.1 & 19.1 \\
\hline$\sigma$ & 2.3 & 2.1 & 3.0 & 4.5 \\
\hline MAC1c & 9.3 & 16.4 & 20.6 & 23.2 \\
\hline$\sigma$ & 4.2 & 4.4 & 3.3 & 1.8 \\
\hline MAC3 & 35.6 & 44.0 & 53.3 & 62.1 \\
\hline$\sigma$ & 3.9 & 2.9 & 6.0 & 13.8 \\
\hline MAC4 & 7.5 & 11.4 & 15.6 & 19.6 \\
\hline$\sigma$ & 3.1 & 1.4 & 0.8 & 3.7 \\
\hline EAC1 & 98.3 & 100.7 & 102.6 & 112.5 \\
\hline$\sigma$ & 10.2 & 3.4 & 3.2 & 3.1 \\
\hline EAC2 & 16.3 & 22.0 & 27.1 & 35.7 \\
\hline$\sigma$ & 2.2 & 6.7 & 6.7 & 7.6 \\
\hline
\end{tabular}


Alternatively, the air cleaner efficiencies were calculated by subtracting the deposition with the system on (values from Table 2) from the total decay rates. This method treats the additional particle removal as deposition to the room surfaces rather than as part of the filter removal. These average air cleaner efficiencies and their standard deviations are presented in Table 6.

Table 6 Decay Test Efficiencies (Subtracting System-On Deposition)

\begin{tabular}{|l|c|c|c|c|}
\hline Air Cleaner & $\begin{array}{c}\boldsymbol{\eta} \\
\mathbf{3 - . 5} \mu \mathbf{m} \\
(\boldsymbol{\%})\end{array}$ & $\begin{array}{c}\boldsymbol{\eta} \\
\mathbf{. 5 - . 7 \mu \mathbf { m }} \\
(\boldsymbol{\%})\end{array}$ & $\begin{array}{c}\boldsymbol{\eta} \\
\mathbf{. 7 - 1 . 0 \mu \mathbf { m }} \\
(\boldsymbol{\%})\end{array}$ & $\begin{array}{c}\boldsymbol{\eta} \\
\mathbf{1 . 0 - 5 . 0} \boldsymbol{\mu m} \\
(\boldsymbol{\%})\end{array}$ \\
\hline MAC1a & 1.8 & 2.8 & 4.0 & 5.8 \\
\hline $\boldsymbol{\sigma}$ & 1.4 & 2.3 & 3.4 & 4.6 \\
\hline MAC1b & 3.9 & 3.4 & 3.2 & 2.2 \\
\hline $\boldsymbol{\sigma}$ & 2.2 & 2.1 & 3.2 & 4.5 \\
\hline MAC1c & 2.3 & 7.1 & 7.3 & 5.7 \\
\hline $\boldsymbol{\sigma}$ & 4.1 & 4.3 & 3.2 & 1.7 \\
\hline MAC3 & 28.8 & 34.9 & 40.3 & 45.1 \\
\hline $\boldsymbol{\sigma}$ & 4.2 & 2.5 & 5.6 & 13.3 \\
\hline MAC4 & 0.3 & 1.6 & 1.7 & 1.4 \\
\hline $\boldsymbol{\sigma}$ & 3.2 & 1.6 & 0.9 & 3.5 \\
\hline EAC1 & 91.7 & 91.9 & 90.0 & 95.9 \\
\hline $\boldsymbol{\sigma}$ & 10.3 & 3.5 & 3.2 & 3.0 \\
\hline EAC2 & 8.1 & 11.0 & 11.4 & 15.0 \\
\hline $\boldsymbol{\sigma}$ & 2.1 & 6.6 & 6.5 & 7.2 \\
\hline
\end{tabular}

\section{Filtration efficiencies from direct measurements}

As mentioned above and shown in Figure 3, particle samples were taken in 3 locations inside the HVAC ducts: immediately upstream and downstream of the air cleaner and downstream of the standard furnace filter. The in-duct measurements were used to directly calculate filtration efficiencies using equation 5.

$\eta_{\text {direct }}=1-\frac{C_{\text {downstream }}}{C_{\text {upstream }}}$

The particle counts used in equation 5 were hourly averages of $50 \mathrm{~s}$ to $60 \mathrm{~s}$ particle counts taken every ten minutes. Since the upstream and downstream particle counts were taken as consecutive samples, an attempt was made to find extended periods of data with near steady state particle concentrations (see for example the data shown in Figure 8). Also, it was necessary to use measurements without the diluter to avoid getting particle counts near zero for the larger size particles with the more efficient filters. 


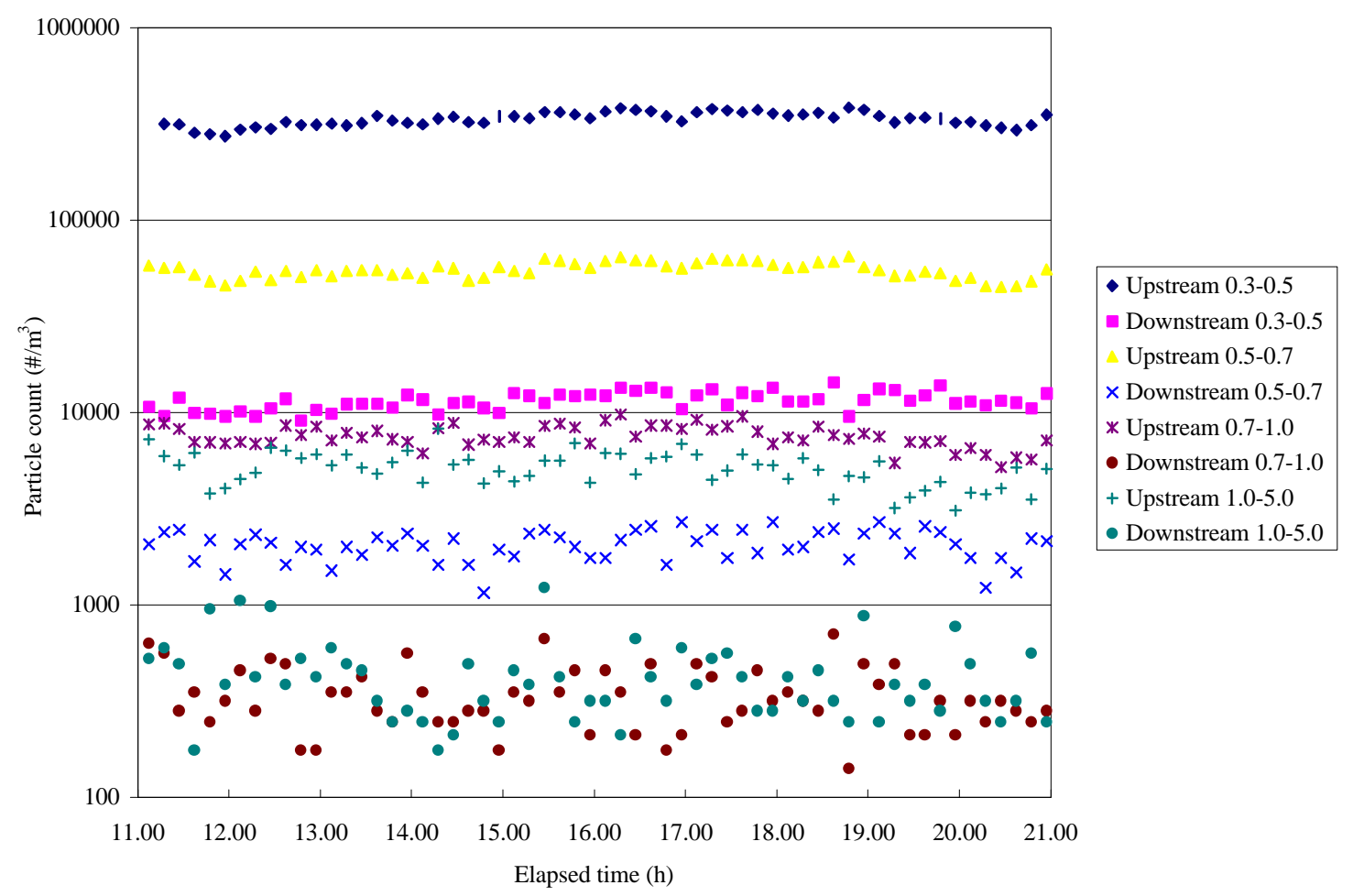

Figure 8 Sample In-duct Particle Counts for EAC1

A summary of the average direct measurement filtration efficiencies along with standard deviations calculated from at least five single hour intervals is shown in Table 7. Figure 9 compares the filtration efficiencies estimated with the three methods for air cleaners MAC1a, MAC1b, MAC3, EAC1, and EAC2. Figure 9 shows that the direct method yielded results close to the decay minus system-on depositions method for nearly all air cleaners and particle size ranges. However, the decay minus system-off depositions consistently yields significantly higher estimates due to the inclusion of deposition in the ductwork and additional deposition in the room as part of the filtration efficiency.

Table 7 Direct Measurement Filtration Efficiencies

\begin{tabular}{|l|c|c|c|c|}
\hline Air Cleaner & $\begin{array}{c}\boldsymbol{\eta} \\
\mathbf{3 - . 5} \mu \mathrm{m} \\
(\boldsymbol{\%})\end{array}$ & $\begin{array}{c}\boldsymbol{\eta} \\
\mathbf{. 5 - . 7} \boldsymbol{\mu m} \\
(\boldsymbol{\%})\end{array}$ & $\begin{array}{c}\boldsymbol{\eta} \\
\mathbf{7 - 1 . 0} \boldsymbol{\mu m} \\
(\boldsymbol{\%})\end{array}$ & $\begin{array}{c}\boldsymbol{\eta} \\
\mathbf{1 . 0 - 5 . 0} \boldsymbol{\mu m} \\
(\boldsymbol{\%})\end{array}$ \\
\hline none & 0.24 & 0.18 & -0.61 & -8.48 \\
\hline $\boldsymbol{\sigma}$ & 0.24 & 0.49 & 1.07 & 3.19 \\
\hline MAC1a & 1.41 & 2.21 & 2.68 & 9.06 \\
\hline $\boldsymbol{\sigma}$ & 0.52 & 0.84 & 3.67 & 5.26 \\
\hline MAC1b & 4.81 & 5.47 & 6.52 & 7.92 \\
\hline $\boldsymbol{\sigma}$ & 3.65 & 4.31 & 5.58 & 14.87 \\
\hline MAC3 & 25.96 & 29.74 & 33.39 & 36.67 \\
\hline $\boldsymbol{\sigma}$ & 1.00 & 1.58 & 2.56 & 3.45 \\
\hline EAC1 & 96.57 & 96.26 & 95.45 & 91.46 \\
\hline $\boldsymbol{\sigma}$ & 0.15 & 0.29 & 0.55 & 1.77 \\
\hline EAC2 & 7.27 & 9.56 & 10.12 & 13.07 \\
\hline $\boldsymbol{\sigma}$ & 0.88 & 1.29 & 1.91 & 6.14 \\
\hline
\end{tabular}




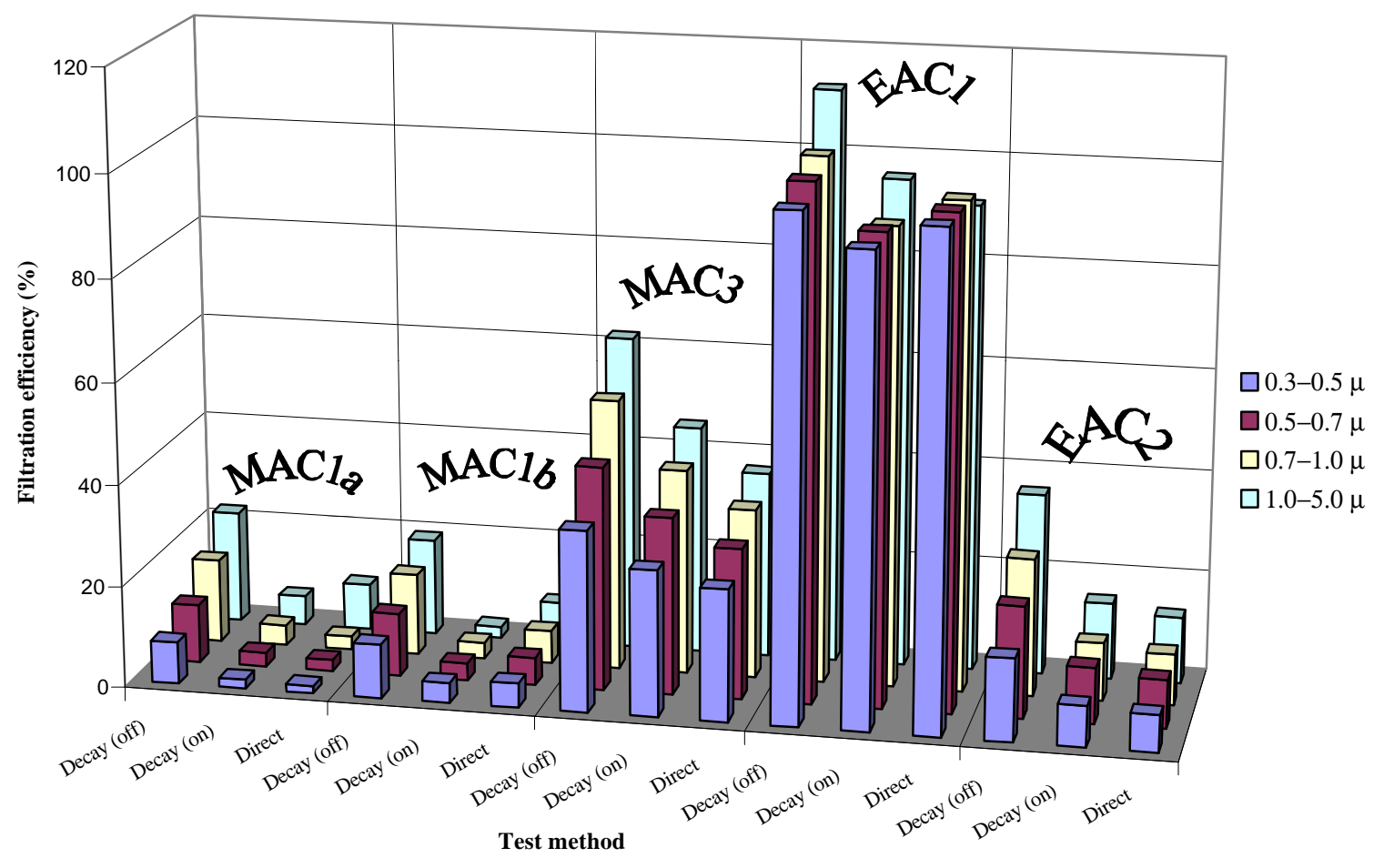

Figure 9 - Comparison of filtration efficiencies from three test methods

Particle generator source strengths

For the purpose of modeling in CONTAM, the source strength of the particle generator was estimated following the analysis described by Traynor for determining pollutant emissions from a gas-fired range (Traynor et al. 1982). With a constant indoor source and letting C(0) equal the indoor concentration at time zero, the solution to equation 1 can be written as:

$C_{\text {in }}(t)=\frac{a P C_{\text {out }}+\frac{S}{V}}{k^{*}}\left[1-e^{-k^{*} t}\right]+C(0) e^{-k^{*} t}$

By rearranging, the source strength can be found from the increase in $\mathrm{C}_{\text {in }}$ after time $\mathrm{T}$ (equation 3 of Traynor et al. 1982):

$\frac{S}{V}=k^{*} \frac{C(T)-C(0) e^{-k^{*} T}}{\left[1-e^{-k^{*} T}\right]}-a P C_{o u t}$

Since there is the possibility of inconsistency of setting the air pressure regulator on the particle generator and of depletion of particles in the reservoir mixture, the particle generator source strength was tested before and after the EAC1 and MAC1 tests described in the simulation section of this report. Table 9 gives the resulting source strengths by particle size for each one 
hour test and the average source strength. The source strength tests were performed with measurements through the diluter and a nominal multiplier of 100 was applied to the results.

Table 8 Particle Generator Source Strength

\begin{tabular}{|l|c|c|c|c|}
\hline & $\begin{array}{c}0.3-0.5 \mu \mathrm{m} \\
\left(\# / \mathrm{m}^{3} \mathrm{~h}\right)\end{array}$ & $\begin{array}{c}0.5-0.7 \mu \mathrm{m} \\
\left(\# / \mathrm{m}^{3} \mathrm{~h}\right)\end{array}$ & $\begin{array}{c}0.7-1.0 \mu \mathrm{m} \\
\left(\# / \mathrm{m}^{3} \mathrm{~h}\right)\end{array}$ & $\begin{array}{c}1.0-5.0 \mu \mathrm{m} \\
\left(\# / \mathrm{m}^{3} \mathrm{~h}\right)\end{array}$ \\
\hline Before & 21300000 & 3820000 & 900000 & 241000 \\
\hline After & 23800000 & 2630000 & 1030000 & 224000 \\
\hline Average & 22500000 & 3230000 & 966000 & 233000 \\
\hline
\end{tabular}

Ozone generation

As mentioned in the air cleaner description above, one consequence of operating EAC1 is the generation of ozone. An example of the ozone buildup due to EAC1 operation, and its subsequent decay after turning off EAC1, is shown in Figure 10. Table 8 summarizes the average indoor and outdoor ozone concentrations measured during the decay periods while testing EAC1. The ozone concentrations in Table 8 should not be taken as indicative of the concentrations that would result in a typical residential application of EAC1 because the test house has a much smaller volume and is tighter than the typical house. EAC2 was found to produce no ozone as claimed.

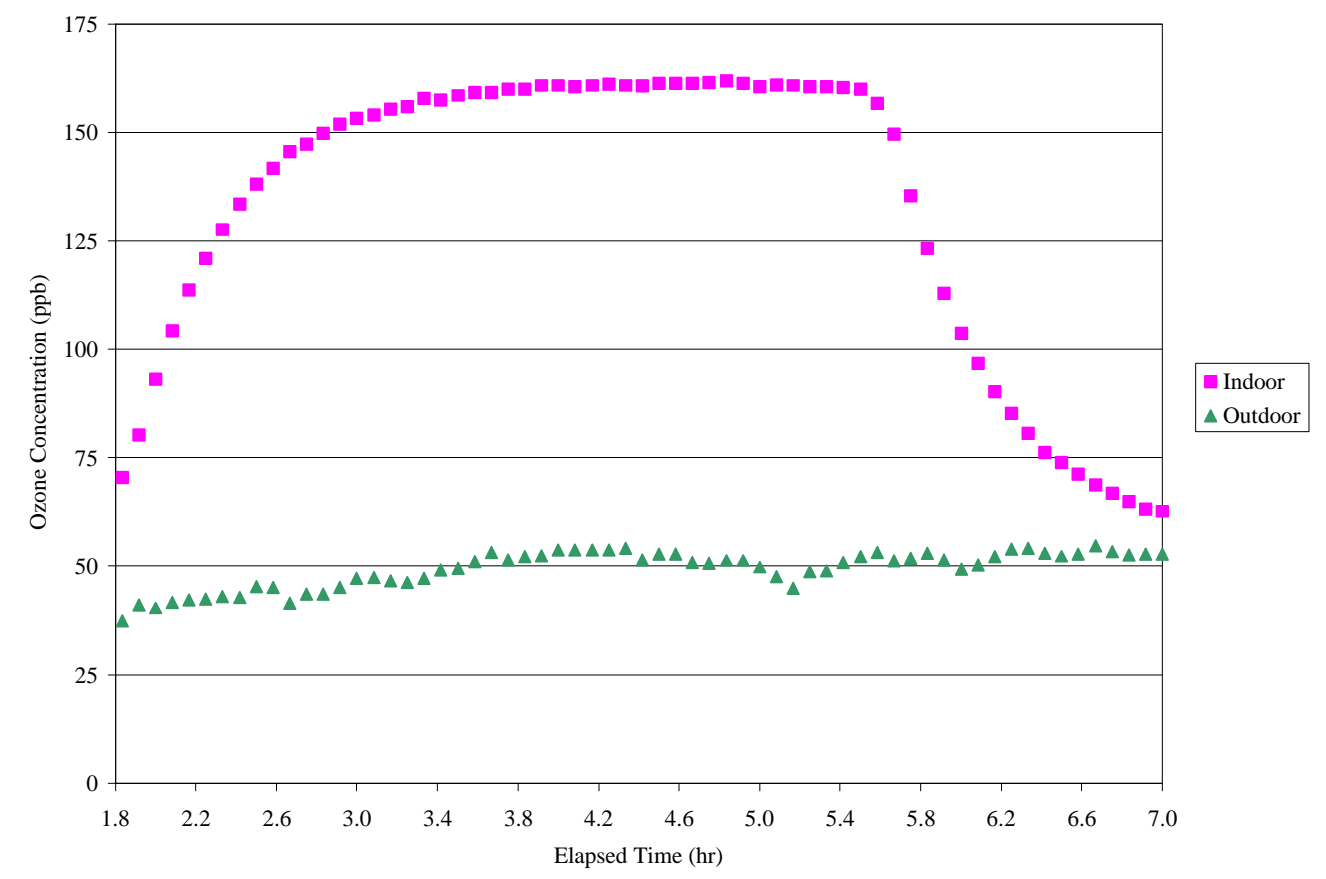

Figure 10 Transient Ozone Concentration due to EAC1 Operation

The ozone generation rate of EAC1 was estimated using Equation 6. Estimates were made for five one-hour EAC1 operation periods similar to Figure 10. Table 8 summarizes the initial and final indoor ozone concentrations, average outdoor ozone concentrations, and measured air change rates for the five periods. The ozone concentrations in Table 8 should not be taken as indicative of the concentrations that would result in a typical residential application of EAC1 because the test house has a much smaller volume and is tighter than the typical house. The decay constant, $\mathrm{k}$, was taken from the literature as concerns about the continued generation of ozone 
after turning EAC1 off prevented using measured decay rates. Nazaroff et al. (1993) summarized measured ozone decay rates ranging from $1.44 \mathrm{~h}^{-1}$ for a stainless steel room to $7.56 \mathrm{~h}^{-1}$ for a cleanroom. Since the test house is furnished approximately like an office, the average value reported for offices $\left(3.7 \mathrm{~h}^{-1}\right)$ was chosen. The penetration factor, $\mathrm{P}$, was assumed to be 1.0, although varying it had little effect on the estimates. The average ozone generation rate for the five test periods was $5.4 \times 10^{-4} \mathrm{~m}^{3} / \mathrm{h}$ with a standard deviation of $9.4 \times 10^{-5} \mathrm{~m}^{3} / \mathrm{h}$.

EAC2 was found to produce no ozone as claimed by the manufacturer.

Table 9 Ozone Concentrations During EAC1 Tests

\begin{tabular}{|c|c|c|c|c|}
\hline Test & $\begin{array}{c}\mathrm{C}_{\text {initial }} \\
(\mathrm{ppb}(\mathrm{v}))\end{array}$ & $\begin{array}{c}\mathrm{C}_{\text {final }} \\
(\mathrm{ppb}(\mathrm{v}))\end{array}$ & $\begin{array}{c}\mathrm{C}_{\text {out }} \\
(\mathrm{ppb}(\mathrm{v}))\end{array}$ & $\begin{array}{c}\text { Air change } \\
\text { rate } \\
\left(\mathrm{h}^{-1}\right)\end{array}$ \\
\hline $\mathrm{d} 56$ & 70 & 147 & 42 & 0.19 \\
\hline $\mathrm{d} 56$ & 63 & 135 & 50 & 0.14 \\
\hline $\mathrm{d} 56$ & 63 & 151 & 39 & 0.12 \\
\hline $\mathrm{d} 56$ & 93 & 182 & 52 & 0.22 \\
\hline $\mathrm{d} 56$ & 114 & 200 & 22 & 0.22 \\
\hline
\end{tabular}

Long term test of MAC5

A long term test of one mechanical air cleaner was performed as an initial attempt to characterize the change in filter performance with loading for modeling purposes. For the long term test, a new mechanical air cleaner cartridge (MAC5) was inserted in the system and the initial performance was measured by the decay method with the box method of particle generation as described above. Then the HVAC system was operated continuously with particle decay tests performed at approximately one week intervals. Also, the filter cartridge was weighed weekly to determine if the filter loading could be tracked by the weight.

The analysis of the results indicates that a weak trend of increasing pressure drop and filtration efficiency for the largest particles could be seen after about 80 days of operation (see Figure 11). However, the relative cleanliness of the NIKE test house (as evidenced by the lack of a mat of fibers on the filter) limited the usefulness of this test. In fact, the variability in filter weight correlated with relativity humidity better than time in service (see Figure 12) This test will be repeated in an occupied house which should involve more significant and realistic loading of the filter. 


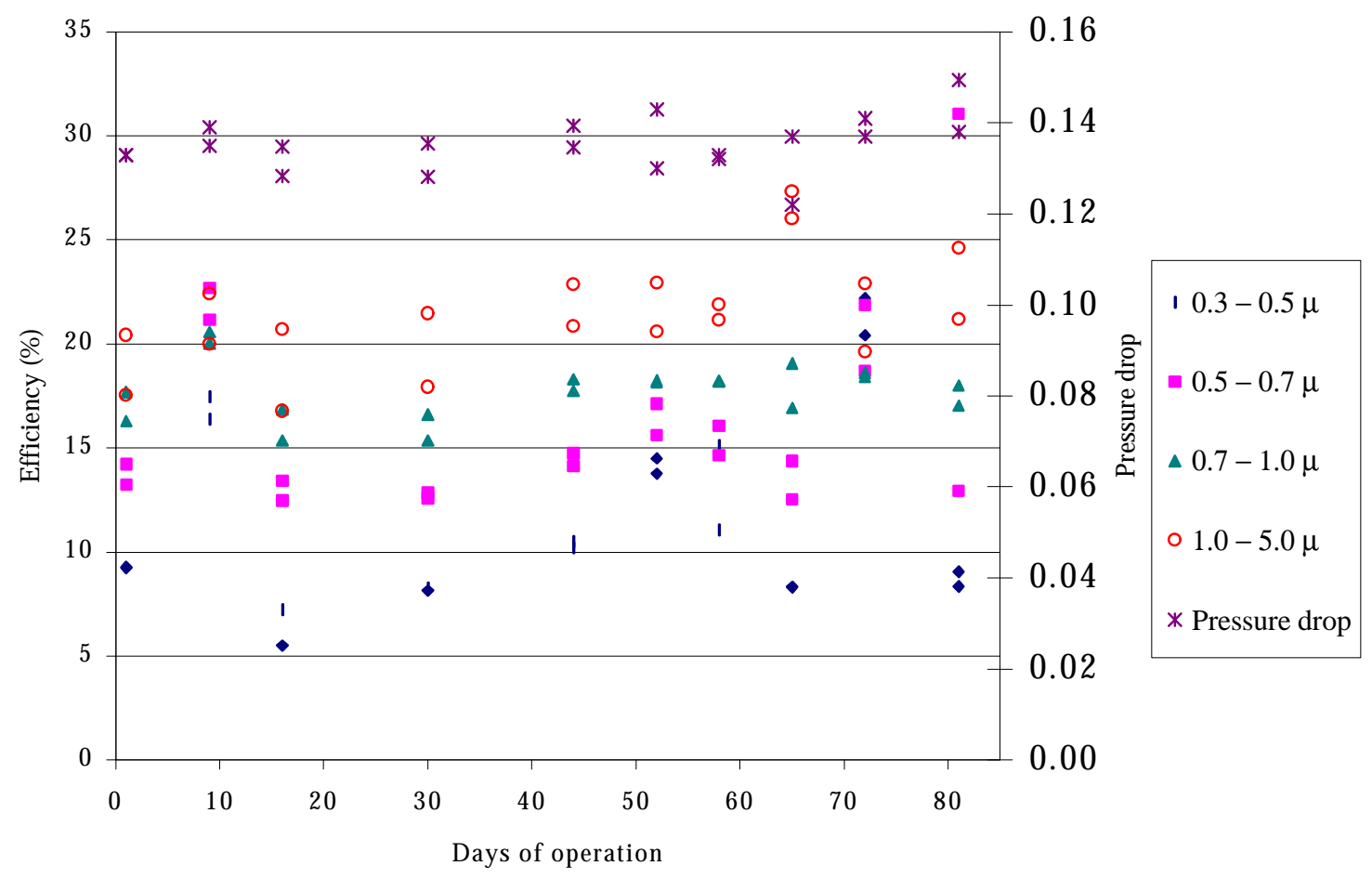

Figure 11 Long Term Efficiency Test of MAC5

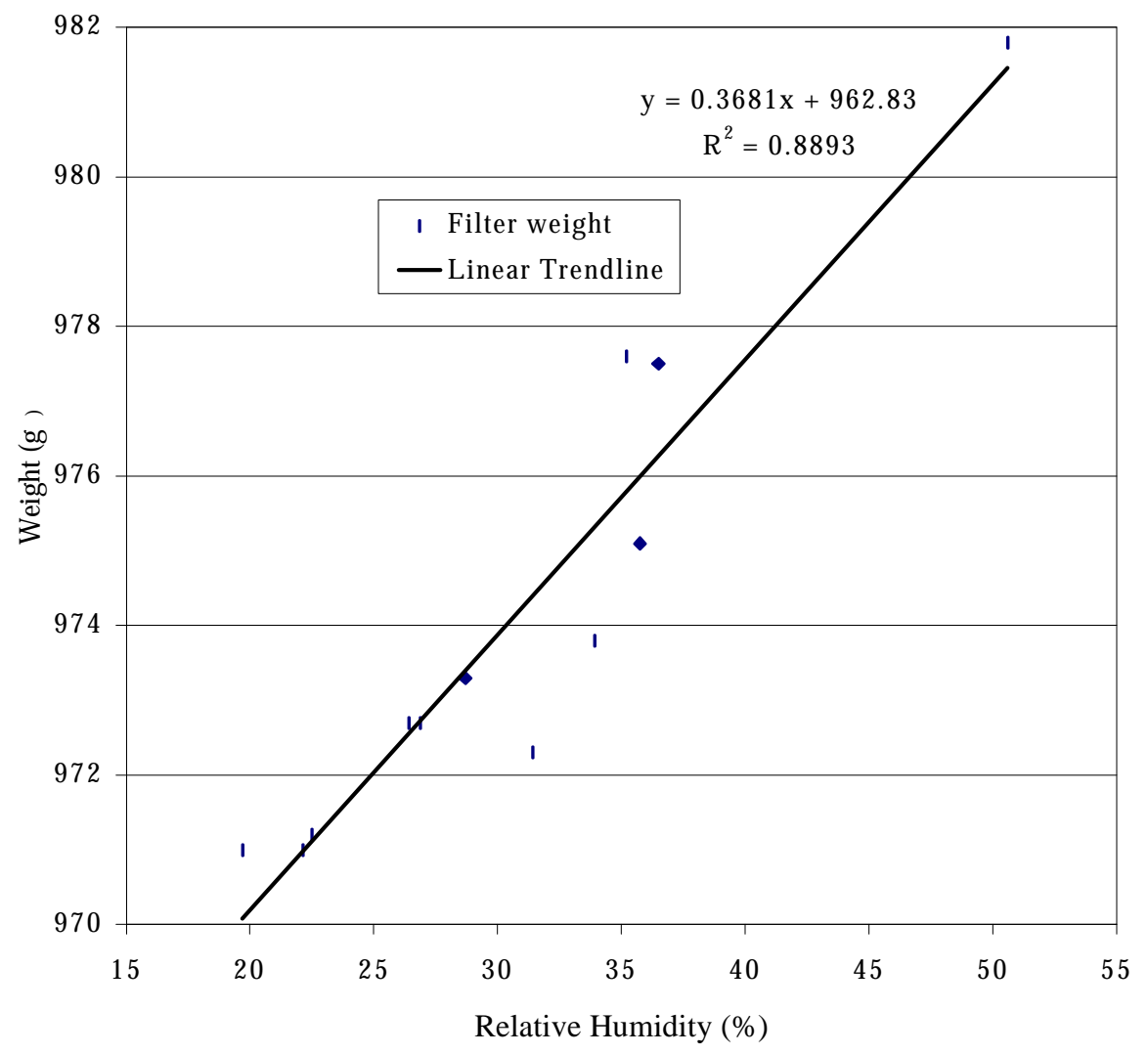

Figure 12 Correlation of Filter Weight and Relative Humidity 


\section{Simulation Procedure}

This section of the report describes the CONTAM model of the test house. This model was used to compare CONTAM predictions of air change rates and pollutant concentrations to measurements.

\section{CONTAM Model}

The test house described in the measurement section was modeled using CONTAM (Walton 1997) - a program for analyzing the air movement and IAQ in multizone buildings. CONTAM has a graphic interface, or Sketchpad, used to create and edit a description of a building's features relating to airflow and the generation and removal of contaminants. This data along with ambient weather and pollutant contaminant data are used to calculate the airflows and concentrations of indoor contaminants.

पambt

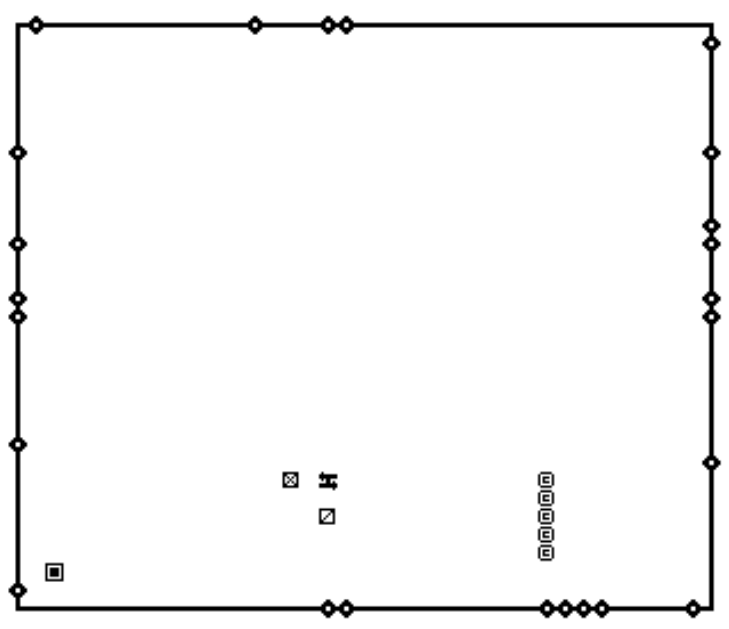

Figure 13 CONTAM Sketchpad Representation of Test House

The graphical representation of the main floor of the test house as it appears in CONTAM is shown in Figure 13. The test house attic was included in the model but is not shown. Ideally, the air leakage model of the house could be created by performing leakage tests on the individual airflow paths (wall joints, windows, etc.). However, such an impractical experimental effort was avoided by a two-step modeling process. First, individual air leakage elements were created in CONTAM based on best estimate values from Table 25-3 of the ASHRAE Handbook of Fundamentals (ASHRAE 1997). This step ensures a realistic distribution of appropriate airflow elements. Then, the leakage values of the individual elements were adjusted such that the resulting flows from a simulated blower door test matched those from a real blower door test. A 
comparison of the simulated and real blower door test results is shown in Figure 14, and the resulting airflow leakage elements are summarized in Table 10. The leakage elements in Table 10 are for a reference pressure difference of $4 \mathrm{~Pa}$ and a discharge of 1.0 with a flow exponent of 0.63 based on the blower door test.

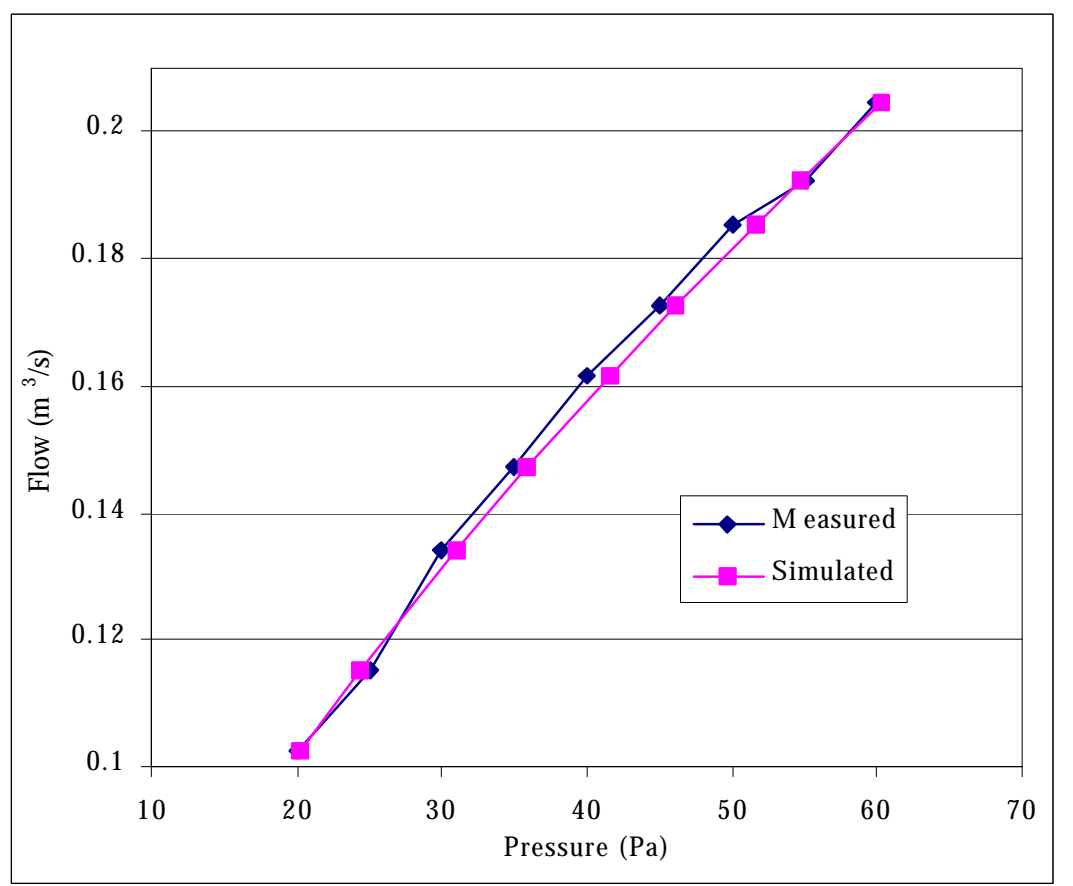

Figure 14 Measured and Simulated Blower Door Test Results

Table 10 Air Leakage Values

\begin{tabular}{|l|c|}
\hline Airflow element description & $\begin{array}{c}\text { Effective Leakage } \\
\text { Area at 4 Pa }\end{array}$ \\
\hline Wall-wall joint & $0.864 \mathrm{~cm}^{2} / \mathrm{m}$ \\
\hline Ceiling-wall joint & $0.864 \mathrm{~cm}^{2} / \mathrm{m}$ \\
\hline Floor-wall joint & $2.08 \mathrm{~cm}^{2} / \mathrm{m}$ \\
\hline Window & $3.37 \mathrm{~cm}^{2}$ \\
\hline Ceiling & $0.908 \mathrm{~cm}^{2} / \mathrm{m}^{2}$ \\
\hline Door frame & $1.7 \mathrm{~cm}^{2} / \mathrm{m}^{2}$ \\
\hline Door (distributed at 3 locations vertically) & $21 \mathrm{~cm}^{2}$ \\
\hline Wall penetration (4 on N wall, 2 on S wall, 1 on W wall) & $1.3 \mathrm{~cm}^{2}$ \\
\hline Ceiling penetration & $2.13 \mathrm{~cm}^{2}$ \\
\hline Attic vent (on N and S walls) & $0.045 \mathrm{~m}^{2}$ \\
\hline Attic vent (on E and W walls) & $613 \mathrm{~cm}^{2}$ \\
\hline
\end{tabular}




\section{Comparison of Predictions and Measurements}

This section of the report compares the results of model predictions and measurements for two of the tested air cleaners. The two air cleaners chosen for comparison of simulations and measurements were the electronic air cleaner EAC1 and the mechanical air cleaner MAC1b. Both cases modeled cover a $24 \mathrm{~h}$ time period during which the HVAC system was operated continuously with an air cleaner installed and operating. In the results below, the $24 \mathrm{~h}$ test with MAC1b is called case $\mathrm{d} 72$ and the $24 \mathrm{~h}$ test with EAC1 is called case $\mathrm{d} 74$. In both cases, the particle generator was used as a continuous source of particles for four hours. During the $24 \mathrm{~h}$ tests, infiltration rates, indoor and outdoor particle counts, temperatures, duct flow, and relative humidities were measured as described in the procedure section. The temperature in the attic was not measured but was modeled as equal to the average of the indoor and outdoor temperature.

For each air cleaner, two approaches to modeling the air cleaner performance were considered. First, the air cleaners were modeled with the removal efficiencies determined by direct in-duct measurements (values in Table 7) in combination with the deposition rates determined for system on (values in Table 2). Second, the total removal efficiencies associated with the air cleaner as determined by decay tests (values in Table 5) were used in combination with the deposition rates for system off (values in Table 2).

\section{Statistical Evaluation of Model Predictions}

ASTM D5157 "Standard Guide for Statistical Evaluation of Indoor Air Quality Models" provides quantitative and qualitative tools for evaluation of IAQ models (ASTM 1991). It provides guidance in choosing data sets for model evaluation and focuses on evaluating the accuracy of indoor concentrations predicted by a model. As part of the comparison of CONTAM predictions to test house measurements, the ASTM D5157 criteria were applied. The data sets collected during this study meet the ASTM D5157 criteria for model evaluation as they are entirely independent of the data used to develop the model and to estimate model inputs. Also, the data is of sufficient temporal and spatial detail to evaluate the CONTAM predictions of both inert pollutants and particles in a single zone.

ASTM D5157 provides three statistical tools for evaluating the accuracy of IAQ predictions and two additional statistical tools for assessing bias. Values for these statistical criteria are provided to indicate whether the model performance is adequate. The tools for assessing agreement between predictions include:

1) The correlation coefficient of predictions vs. measurements should be 0.9 or greater.

2) The line of regression between the predictions and measurements should have a slope between 0.75 and 1.25 and an intercept less than $25 \%$ of the average measured concentration.

3) The normalized mean square error (NMSE) should be less than 0.25. NMSE is calculated as:

$$
N M S E=\sum_{i=1}^{N}\left(C_{p i}-C_{o i}\right)^{2} / 2 \bar{C}_{o} \bar{C}_{p}
$$

where $\mathrm{C}_{\mathrm{p}}$ is the predicted concentration and $\mathrm{C}_{\mathrm{o}}$ is the observed concentration.

ASTM D5157 also provides two statistical measures of bias with values for judging adequate model performance. These bias measures include: 
1) Normalized fractional bias (FB) of the mean concentrations. Fractional bias should be 0.25 or lower and is calculated as:

$$
F B=2\left(\bar{C}_{p}-\bar{C}_{o}\right) /\left(\bar{C}_{p}+\bar{C}_{o}\right)
$$

2) Fractional bias based on the variance (FS) which should be 0.5 or lower. FS is calculated as:

$$
F B=2\left(\sigma^{2} \bar{C}_{p}-\sigma^{2} \bar{C}_{o}\right) /\left(\sigma^{2} \bar{C}_{p}+\sigma^{2} \bar{C}_{o}\right)
$$

\section{Infiltration Rates}

The building air change rate is the best parameter to compare the simulated and measured airflow results as it is a commonly used parameter to evaluate the adequacy of building ventilation.

Measured air change rates were determined from log curve fits to the $\mathrm{SF}_{6}$ tracer gas decay data as described above. Simulated air change rates were determined from the CONTAM results by adding all of the flows to the building from the ambient zone and dividing by the building volume. Figures $15 \mathrm{a}$ and $15 \mathrm{~b}$ compare the one hour air change rates for cases d72 and d74, respectively. For Case d72, the average of the hourly measured and simulated air change rates were both 0.24 $\mathrm{h}^{-1}$. For Case d74, the average of the hourly measured and simulated air change rates were $0.22 \mathrm{~h}$ ${ }^{1}$ and $0.21 \mathrm{~h}^{-1}$, respectively. For case d72, the absolute average percent difference between the measured and modeled hourly air exchange rates was $20 \%$ with the percent differences ranging from $-31 \%$ to $40 \%$. For case d74, the absolute average percent difference between the measured and modeled hourly air exchange rates was $16 \%$ with the percent differences ranging from $-46 \%$ to $29 \%$.
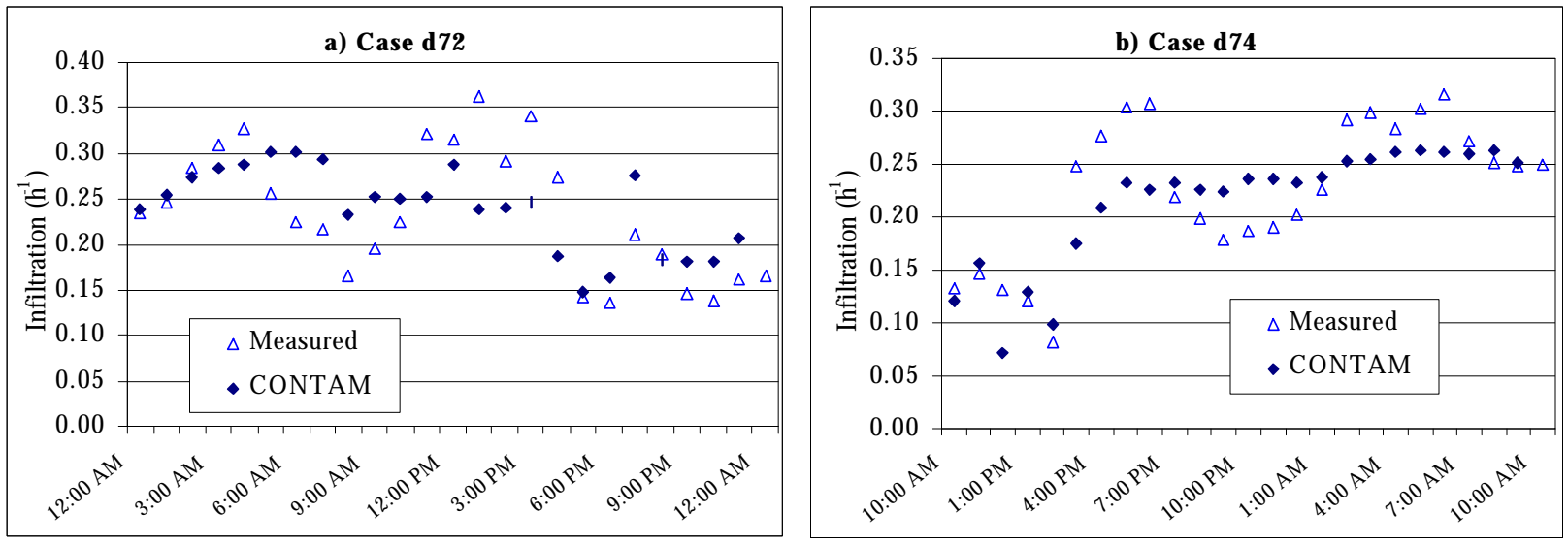

Figure 15 Measured and Simulated Air Change Rates

\section{Tracer Gas Concentrations}

Since $\mathrm{SF}_{6}$ was injected during the $24 \mathrm{~h}$ tests to measure air change rates, it was included in the simulation to compare predictions to measurements for an inert indoor air contaminant. An inert pollutant is the simplest contaminant to model as there is no need to include deposition, air cleaning, or contaminant reactions in the model. The resulting concentration of the contaminant will depend only on the calculated airflow rates, outdoor concentrations, and pollutant source strength and schedule. The outdoor concentration of $\mathrm{SF}_{6}$ was assumed to be zero. Since the 
injection rates and time were not recorded, the source strength used in CONTAM was adjusted such that the increase in concentration over a five minute simulation time step approximately matched the measured increase in concentration.

Figures 16a and $16 \mathrm{~b}$ compare the measured and simulated $\mathrm{SF}_{6}$ concentrations for cases $\mathrm{d} 72$ and $\mathrm{d} 74$, respectively. The simulated $24 \mathrm{~h}$ average $\mathrm{SF}_{6}$ concentration was $11 \%$ less than the average measured value for Case $\mathrm{d} 72$ and $2 \%$ less than the average measured value for Case $\mathrm{d} 74$.
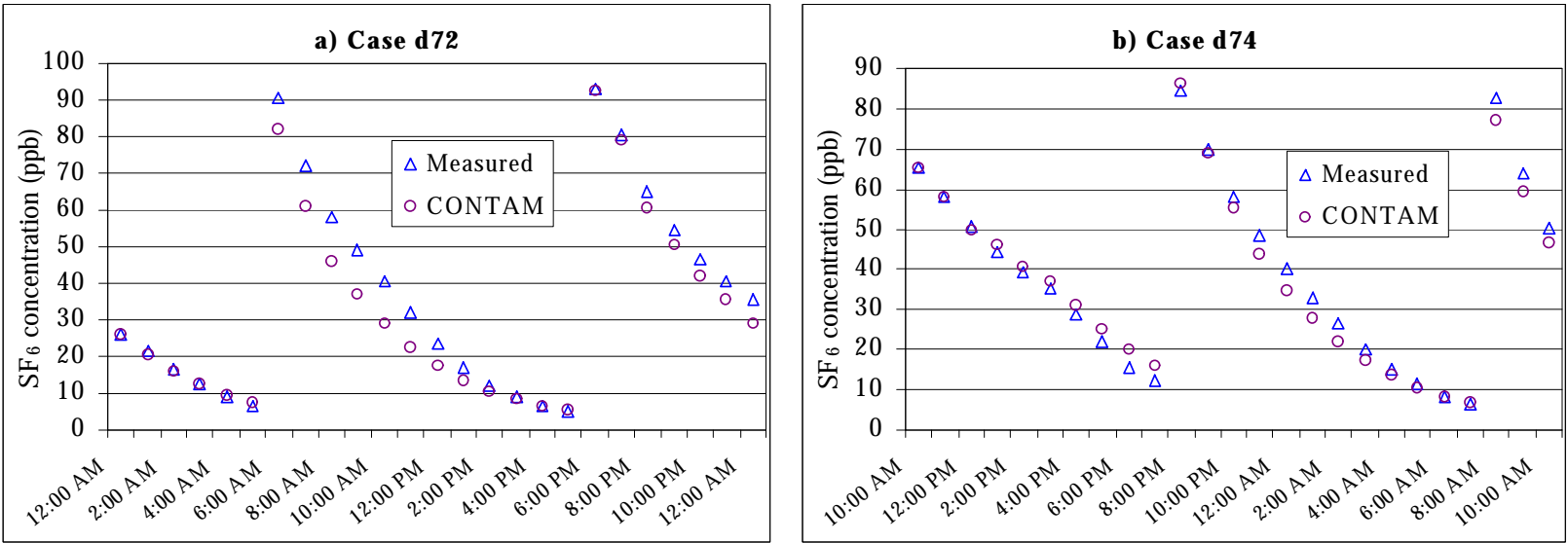

\section{Figure 16 Measured and Simulated Tracer Gas Concentrations}

\section{Mechanical Air Cleaner Performance}

As mentioned above, one of the mechanical air cleaners (MAC1b) was modeled two different ways in CONTAM. First, the air cleaners were modeled with the removal efficiencies determined by direct in-duct measurements (values in Table 7) in combination with the deposition rates determined for system on (values in Table 2). The simulated indoor particle concentrations using this method are presented in Figures 17a through 17d (for each of the four size ranges) along with measured particle counts. The particle counts in Figure 17 (and 18 through 22) were measured through the diluter and were multiplied by 100 to yield total concentrations. For this case the HVAC system with MAC1b installed was operating prior to the start of the test resulting in the initial steady concentrations in Figure 17. The particle generator was on from 10:00 a.m. to 2:00 p.m.

The percent difference between measured and simulated $24 \mathrm{~h}$ average particle concentrations was $8.9 \%$ for $0.3 \mu \mathrm{m}$ to $0.5 \mu \mathrm{m}$ particles, $-6.0 \%$ for $0.5 \mu \mathrm{m}$ to $0.7 \mu \mathrm{m},-17.9 \%$ for $0.7 \mu \mathrm{m}$ to 1.0 $\mu \mathrm{m}$, and $-29.7 \%$ for $1.0 \mu \mathrm{m}$ to $5.0 \mu \mathrm{m}$. The percent differences at any point in time ranged from $-80 \%$ to $72 \%$. 

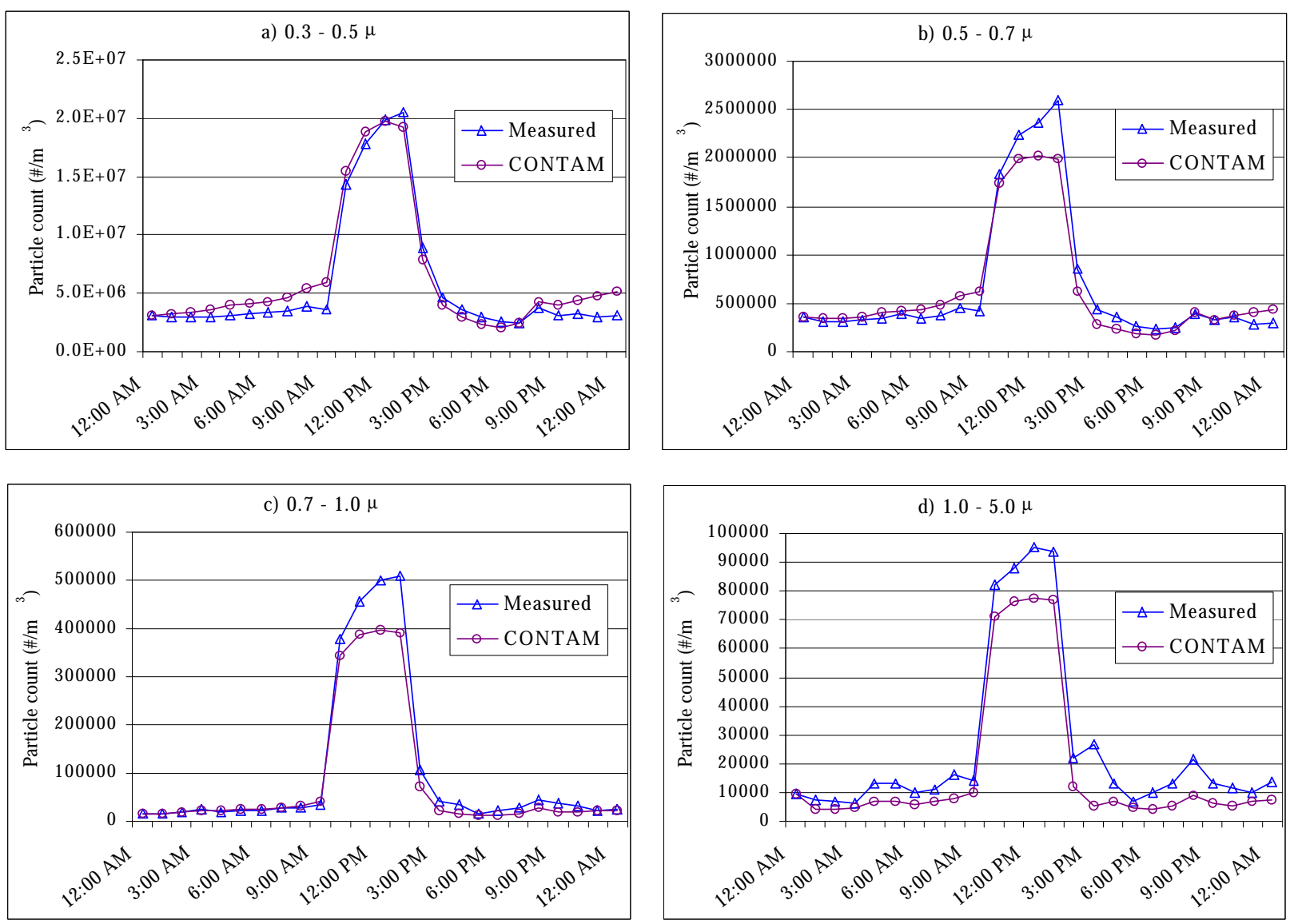

Figure 17 Comparison of Measured and Simulated Particle Counts with Direct MAC1b Filtration Efficiency

Next, MAC1b was modeled for the same case using the total removal efficiencies determined by decay tests (values in Table 5) in combination with the deposition rates for system off (values in Table 2). The simulated indoor particle concentrations using this method are presented in Figures $18 \mathrm{a}$ through $18 \mathrm{~d}$. The percent difference between measured and simulated $24 \mathrm{~h}$ average particle concentrations was $11.5 \%$ for $0.3 \mu \mathrm{m}$ to $0.5 \mu \mathrm{m}$ particles, $-1.2 \%$ for $0.5 \mu \mathrm{m}$ to $0.7 \mu \mathrm{m},-10.3$ $\%$ for $0.7 \mu \mathrm{m}$ to $1.0 \mu \mathrm{m}$, and $-21.4 \%$ for $1.0 \mu \mathrm{m}$ to $5.0 \mu \mathrm{m}$. The percent differences at any point in time ranged from $-75 \%$ to $55 \%$. The CONTAM predictions with this method were slightly closer to the measurements with the exception of the smallest size particles. 

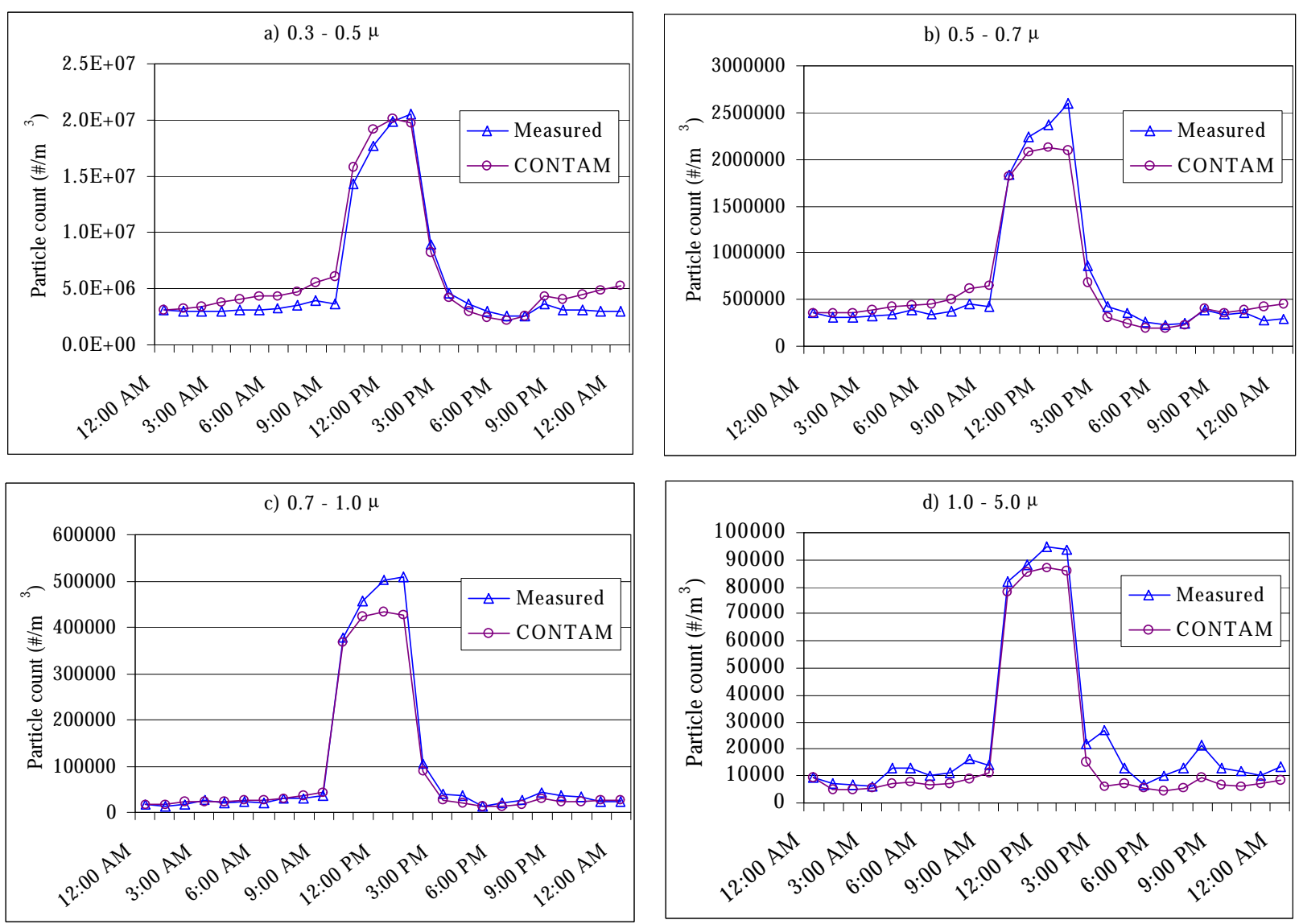

Figure 18 Comparison of Measured and Simulated Particle Counts with Decay Test MAC1b Filtration Efficiency

\section{Electronic Air Cleaner Performance}

Similarly, one of the electronic air cleaners (EAC1) was modeled initially with the removal efficiencies determined by direct in-duct measurements (values in Table 7) in combination with the deposition rates determined for system on (values in Table 2). The simulated indoor particle concentrations using this method and the measured particle counts are presented in Figures 19a through 19d. Unlike the case above, the air cleaner was turned on at the start of the test resulting in the initial sharp decline seen in Figure 19. The particle source was on from 12:00 p.m. to 4:00 p.m.

The percent difference between measured and simulated $24 \mathrm{~h}$ average particle concentrations was $11.7 \%$ for $0.3 \mu \mathrm{m}$ to $0.5 \mu \mathrm{m}$ particles, $12.6 \%$ for $0.5 \mu \mathrm{m}$ to $0.7 \mu \mathrm{m},-15.2 \%$ for $0.7 \mu \mathrm{m}$ to 1.0 $\mu \mathrm{m}$, and $-27.2 \%$ for $1.0 \mu \mathrm{m}$ to $5.0 \mu \mathrm{m}$. The percent differences at any point in time ranged from $-82 \%$ to $142 \%$ but fluctuated much more than for MAC1b. This larger fluctuation is likely due to the smaller absolute particle concentrations in the building as a result of the highly effective air cleaner. 

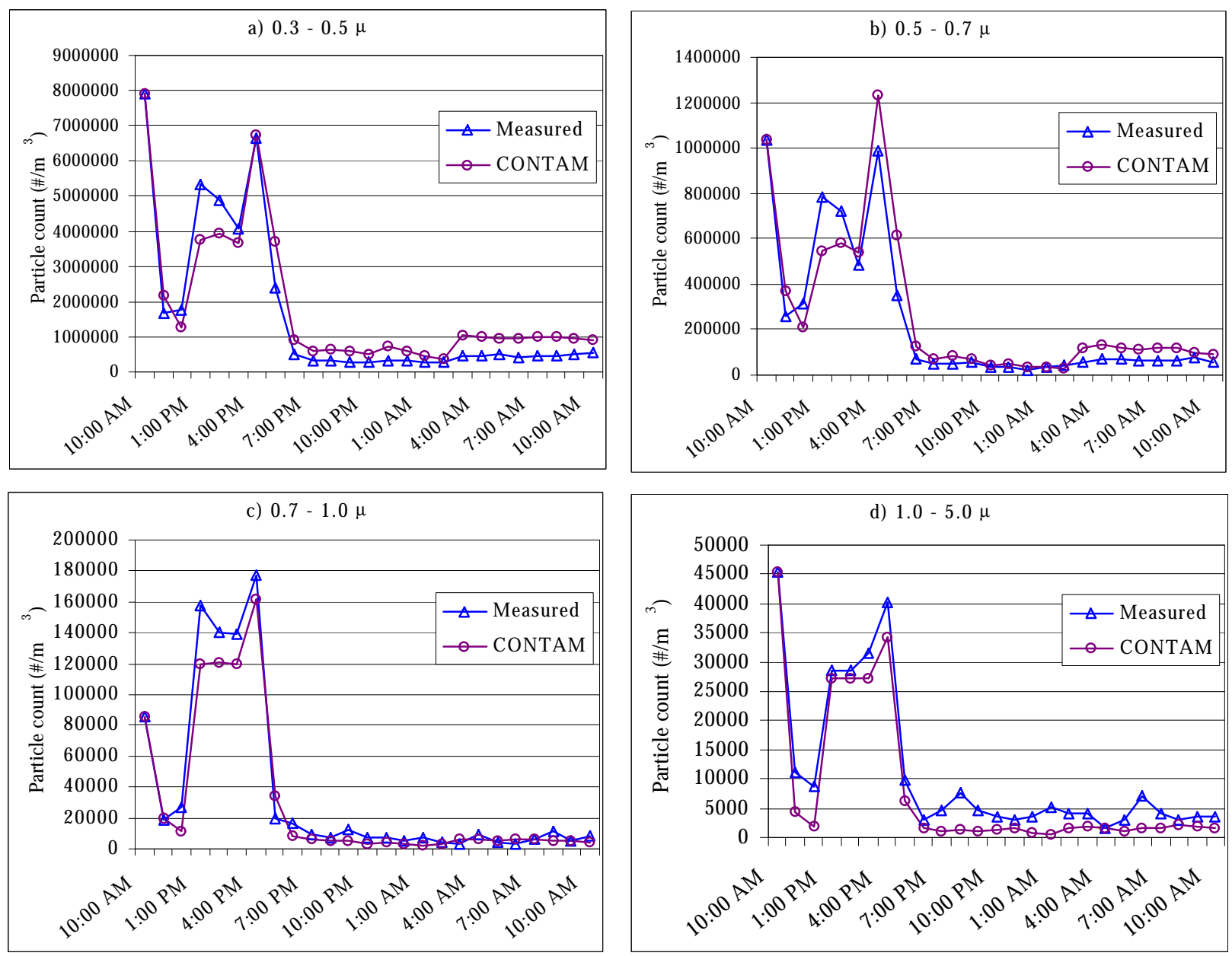

Figure 19 Comparison of Measured and Simulated Particle Counts with Direct EAC1 Filtration Efficiency

Next, EAC1 was modeled for the same case using the total removal efficiencies determined by decay tests (values in Table 5) in combination with the system-off deposition rates (values in Table 2). The simulated indoor particle concentrations using this method are presented in Figures $20 \mathrm{a}$ through $20 \mathrm{~d}$. The percent difference between measured and simulated $24 \mathrm{~h}$ average particle concentrations was $16.0 \%$ for $0.3 \mu \mathrm{m}$ to $0.5 \mu \mathrm{m}$ particles, $16.8 \%$ for $0.5 \mu \mathrm{m}$ to $0.7 \mu \mathrm{m},-9.7 \%$ for $0.7 \mu \mathrm{m}$ to $1.0 \mu \mathrm{m}$, and $-23.4 \%$ for $1.0 \mu \mathrm{m}$ to $5.0 \mu \mathrm{m}$. The percent differences at any point in time ranged just as wide as the previous method from $-87 \%$ to $153 \%$. Almost like the MAC $1 \mathrm{~b}$ predictions, the CONTAM predictions with this method were somewhat closer to the measurements for the two larger size ranges but somewhat further from the measurements for the two smaller size ranges. 

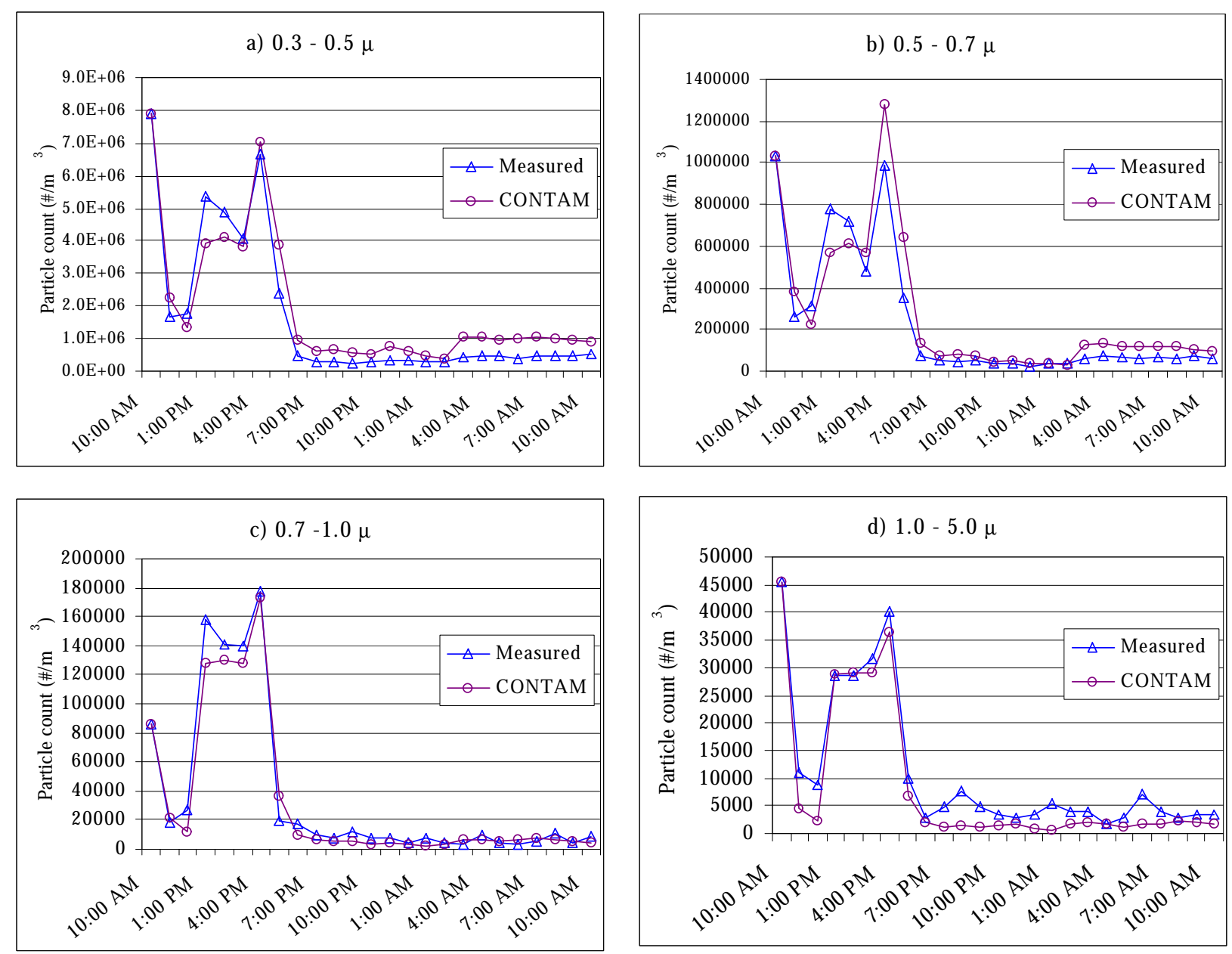

\section{Figure 20 Comparison of Measured and Simulated Particle Counts with Decay Test EAC1 Filtration Efficiency}

\section{Statistical Evaluation}

The statistical measures from ASTM D5157 were calculated for the predicted particle and $\mathrm{SF}_{6}$ concentrations for the cases presented in Figures 16 to 20 above. All of the model predictions met the criteria given above for adequate model performance for all the statistical measures with very few exceptions. For example, the correlation coefficient for all cases was greater than 0.94 for all cases and was 0.98 to 0.99 for all cases except the two smallest size particles with the electronic air cleaner operating. Similarly, the NMSE was less than 0.2 for all cases and was less than 0.1 for many cases. The bias measures fared nearly as well with the model predictions meeting the criteria for all cases except for the predictions for the largest size particles which were slightly outside the adequate criteria for FB. 


\section{IMPACT OF AIR CleANERS}

As an example of how CONTAM would be used to evaluate the impact of IAQ controls, the two cases simulated above with the MAC1b and EAC1 air cleaners were also simulated with a typical furnace filter. The method used was the simulation with filtration efficiency from the decay test (MAC4 data from Table 5 above) as no direct measurement efficiency was available. All the remaining simulation parameters remained the same as discussed above.

The simulated particle concentrations for case $\mathrm{d} 72$ with MAC1b and the typical furnace filter along with measured outdoor particle concentrations are shown in Figures 21a through 21d. The mechanical air cleaner MAC1b reduced the $24 \mathrm{~h}$ average particle concentrations by $15 \%$ for 0.3 $\mu \mathrm{m}$ to $0.5 \mu \mathrm{m}$ particles, $4 \%$ for $0.5 \mu \mathrm{m}$ to $0.7 \mu \mathrm{m}, 2 \%$ for $0.7 \mu \mathrm{m}$ to $1.0 \mu \mathrm{m}$, and $-1 \%$ for 1.0 $\mu \mathrm{m}$ to $5.0 \mu \mathrm{m}$ compared to the furnace filter.
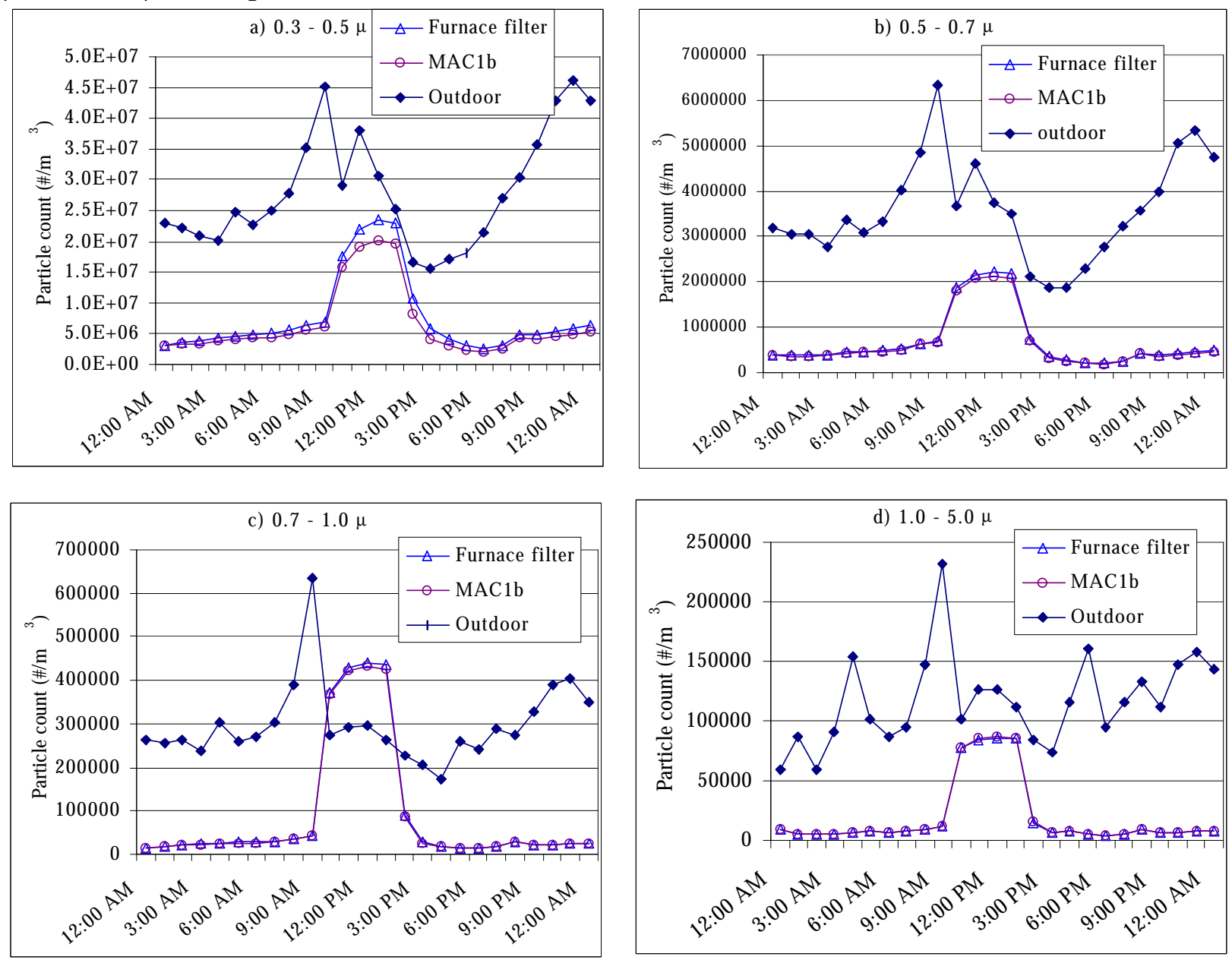

\section{Figure 21 Impact of MAC1b Compared to Furnace Filter}

The simulated particle concentrations for case d74 with EAC1 and the typical furnace filter along with measured outdoor particle concentrations are shown in Figures 22a through 22d. The electronic air cleaner EAC1 reduced the $24 \mathrm{~h}$ average particle concentrations by $85 \%$ for $0.3 \mu \mathrm{m}$ to $0.5 \mu \mathrm{m}$ particles, $78 \%$ for $0.5 \mu \mathrm{m}$ to $0.7 \mu \mathrm{m}, 73 \%$ for $0.7 \mu \mathrm{m}$ to $1.0 \mu \mathrm{m}$, and $67 \%$ for 1.0 $\mu \mathrm{m}$ to $5.0 \mu \mathrm{m}$ compared to the furnace filter. 

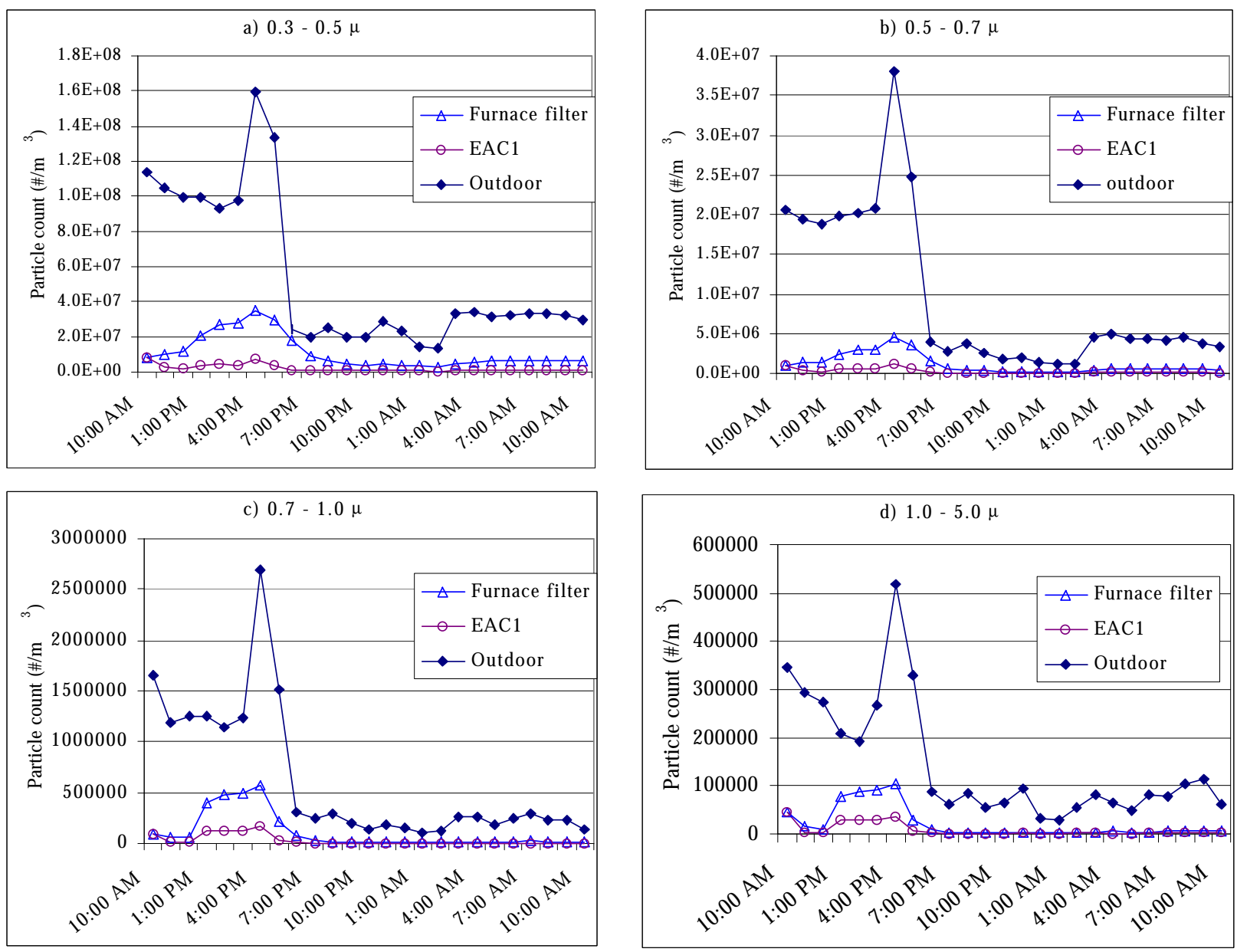

Figure 22 Impact of EAC1 Compared to Furnace Filter 


\section{DISCUSSION}

The primary objective of this effort was to evaluate the capability of the multizone IAQ model CONTAM to simulate the impact of particle air cleaners in a real building subject to real ambient conditions. As shown in Figures 15 through 20, it is possible to adequately predict the air cleaner performance, at least for a single zone building without occupants present. Future work is underway to extend the project to include measurements and predictions of particle air cleaners in an occupied home.

Although both the decay and direct methods resulted in good predictive accuracy, it is not surprising that the decay method was somewhat more accurate than the direct method. This is almost certainly because it yielded a filtration efficiency for the HVAC system and air cleaner as an installed unit. Thus, factors such as leakage around a poor fitting air cleaner and deposition in the ductwork is accounted for in the measured efficiencies. However, for typical design applications, one would not have such an "installed" efficiency available but rather would rely on manufacturer test data that might be similar to the direct method efficiencies. These efficiencies would need to be combined with appropriate deposition factors to account for the total removal of particles. Additional study into the issue of particle removal throughout the HVAC system ductwork and deposition dependence on ventilation flows is needed to enable such modeling.

Another objective of this effort was to identify model development needs. However, based on the comparison of predictions and measurements, it can be concluded that the current CONTAM capabilities for modeling particulate air filters are adequate. The more pressing need is availability of accurate performance data for air cleaning devices and other model input data. A useful but not essential issue for model development is a contaminant model to represent various size fractions of airborne particles. While it is possible to model particles with the current capabilities of CONTAM, a specific contaminant model representing particles would make this task far easier for the CONTAM user. 


\section{ACKNOWLEDGEMENTS}

The authors wish to acknowledge the efforts of Dan Greb, Stuart Dols, Kevin Denton, and Elisabeth Ivy in support of this project. The authors also acknowledge the support of Dilip Vyavaharkar of Carrier Corporation in providing technical information and some of the tested air cleaners. 


\section{REFERENCES}

Abraham ME. "Microanalsis of Indoor Aerosols and the Impact of a Compact High-Efficiency Particulate Air (HEPA) Filter System" (1999) Indoor Air 9:33-40.

ALA. Residential Air Cleaning Devices: Types, Effectiveness, and Health Impact. (1997) American Lung Association.

ANSI/AHAM. Method for Measuring Performance of Portable Household Electric CordConnected Room Air Cleaners. (1988) ANSI/AHAM AC-1-1988, Association of Home Appliance Manufacturers.

ASHRAE. Gravimetric and Dust-Spot Procedures for Testing Air-Cleaning Devices used in General Ventilation for Removing Particulate Matter. ASHRAE Standard 52.1 (1992) American Society of Heating, Refrigerating and Air-Conditioning Engineers, Inc.

ASHRAE. Method of Testing General Ventilation Air-Cleaning Devices for Removal Efficiency by Particle Size. ASHRAE Standard 52.2 (1999) American Society of Heating, Refrigerating and Air-Conditioning Engineers, Inc.

ASHRAE. Practices for Measurement, Testing, Adjusting and Balancing of Building Heating, Ventilation, Air-Conditioning and Refrigeration Systems ASHRAE Standard 111 (1988) American Society of Heating, Refrigerating and Air-Conditioning Engineers, Inc.

ASHRAE. Ventilation for Acceptable Indoor Air Quality. ASHRAE Standard 62 (1999) American Society of Heating, Refrigerating and Air-Conditioning Engineers, Inc.

ASHRAE. Handbook of Fundamentals. (1997) American Society of Heating, Refrigerating and Air-Conditioning Engineers, Inc.

ASTM. Standard Guide for Statistical Evaluation of Indoor Air Quality Models. D5157-91 (1991) American Society for Testing and Materials.

ASTM. Standard Test Method for Determining Air Change in a Single Zone by Means of a Tracer Gas Dilution. E741-95 (1995) American Society for Testing and Materials.

ASTM. Standard Test Method for Determining Air Leakage Rate by Fan Pressurization. E77999 (1999) American Society for Testing and Materials.

Bascom R, Fitzgerald TK, Kesavanathan J, and Swift DL. "A portable air cleaner partially reduces the upper respiratory response to sidestream tobacco smoke" (1996) Appl Occup Environ Hyg 11(6):553-559.

Burch DM, Remmert WE, Krintz DF and Barnes CS. "A Field Study of the Effect of Wall Mass on the Heating and Cooling Loads of Residential Buildings" (1982) Proceedings of Building Thermal Mass Seminar. 
Burroughs HE and Kinzer KE. "Improved Filtration in Residential Environments" (1998)

ASHRAE Journal June 1998, 47-51.

Climet. Climet Instruments Operating Manual for VersaPort 10. (1994) Climet Instruments, Inc.

CMHC. Evaluation of Residential Furnace Filters. (1999) Canada Mortgage and Housing Corporation Research Report.

CR. "Breathe easy" (2000) Consumer Reports, January 2000, 42-46.

GEOMET. Consumer Products Exposure Guidelines: Evaluation of Indoor Air Quality Models (1992) GEOMET Report IE-1980, GEOMET Technologies, Inc.

Hanley JT, Ensor DS, Smith DD and Sparks LE. "Fractional Aerosol Filtration Efficiency of InDuct Ventilation Air Cleaners" (1994) Indoor Air 4:169-178.

Herrlin MK. Air-Flow Studies in Multizone Buildings - Models and Applications (1992) Royal Institute of Technology.

Hinds WC. Aerosol Technology - Properties, Behavior, and Measurement of Airborne Particles (1982) Wiley-Interscience.

Lofcoe NM and Inculet II. "Particulates in domestic premises. I. Ambient levels and central air filtration" (1971) Arch Environ Health 22:230.

Luczynska CM, Li Y, Chapman MD, and Platts-Mills TAE. "Airborne concentrations and particle size distribution of allergen derived from domestic cats (Felis domesticus)" (1990) Am Rev Resp Dis 141:361-367.

Nazaroff WW, Gadgil AJ, and Weschler CJ. "Critique of the Use of Deposition Velocity in Modeling Indoor Air Quality" (1993) Modeling of Indoor Air Quality and Exposure, ASTM STP 1205, American Society for Testing and Materials.

Offerman FJ, Loiselle SA, and Sextro RG. "Performance Comparisons of Six Different Air Cleaners Installed in a Residential Forced-Air Ventilation System" (1991) Proceedings of IAQ '91, American Society of Heating, Refrigerating and Air-Conditioning Engineers, Inc.

Offerman FJ, Sextro RG, Fisk WJ, Grimsrud DT, Nazaroff WW, Nero AV, Revzan KL, and Yater J. "Control of Respirable Particles in Indoor Air with Portable Air Cleaners" (1985) Atmospheric Environment 19:1761-71.

Persily AP. "An Indoor Air Quality Performance Standard for Single-Family Residential Buildings" (1999) Proceedings of Indoor Air 99, 8th International Conference on Indoor Air Quality \& Climate 1:194-199. 
Reisman RE, Mauriello PM, Davis GB, Georgitis JW and DeMasi JM. "A double-blind study of the effectiveness of a high-efficiency particulate air (HEPA) filter in the treatment of patients with perennial allergic rhinitis and asthma" (1990) Journal of Allergy and Clinical Immunology 85:1050-7.

Swanson MC, Agarwal MK, and Reed CE. "An immunochemical approach to aeroallergen quantitation with a new volumetric air sampler; studies with mite, roach, cat, mouse and guinea pig antigens" (1985) J. Allergy Clin. Immunol. 76:724.

Thatcher TL and Layton DW. "Deposition, resuspension, and penetration of particles within a residence" (195) Atmospheric Environment 29:1487-97.

Traynor GW, Anthon DW and Hollowell CD. Technique for Determining Pollutant Emissions from a Gas-fired Range. (1982) Atmospheric Environment Vol. 16:2979-2987.

Wallace L. "Indoor Particles: A Review" (1996) Journal of the Air \& Waste Management Association 46:98-126.

Walton GN. Calculation of inter-room movement for multi-room building analysis (1981) NBSIR 81-2404, National Bureau of Standards.

Walton GN. CONTAM96 User Manual. (1997) NISTIR 6056, NIST.

Yuill GK and Upham RD. A Validation Study of Multizone Air Flow and Contaminant Migration Simulation Programs as Applied to Tall Buildings. (1998) Project Report to ASHRAE, Penn State University. 